\title{
Vendor Management Inventory with consignment contracts and the benefits of cooperative advertising*
}

\author{
Pietro De Giovanni ${ }^{\dagger}$ \\ ESSEC Business School, Paris, France \\ Salma Karray \\ University of Ontario Institute of Technology, Oshawa, Ontario, Canada \\ Guiomar Martín-Herrán \\ IMUVA, Universidad de Valladolid, Valladolid, Spain
}

13th June 2018

\begin{abstract}
Most of the cooperative advertising literature has focused on studying the effects of such programs considering marketing variables. This paper integrates production and inventory management with pricing and advertising considerations to assess the effects of cooperative advertising programs in bilateral monopolies. We consider a supply chain where a Vendor Managed Inventory (VMI) along with a consignment contract is implemented to coordinate the chain. We develop and solve a differential model for two games. The first one is a benchmark scenario where no cooperative advertising is offered, while the manufacturer offers the cooperative program in the second game. The main results show that cooperative advertising programs, usually considered as successful marketing initiatives, can be very difficult to implement in a supply chain undertaking a VMI policy with a consignment contract, in which operations and marketing interface is taken into account. A cooperative program mainly hurts the manufacturer's profits, and can be profit-Pareto-improving only in a few cases. Although the retailer is generally willing to receive a support from the manufacturer, she can opt for a non-cooperative program when the largest part of the supply chain profits goes to the manufacturer. We developed several special cases to strengthen our findings.
\end{abstract}

Keywords: Supply Chain Management; Brick-and-mortal chain; Marketing-Operations Interface; Cooperative advertising; Differential games.

\section{Introduction}

Cooperative advertising programs are monetary incentives offered by manufacturers to their retailers to boost advertising efforts for their products. These programs are widely used in supply chains, with an estimated cost

${ }^{*}$ We are grateful to the editor and three anonymous reviewers for valuable comments and suggestions on an earlier draft of this paper. The second author's research is supported by the Natural Sciences and Engineering Research Council of Canada (NSERC) (Grant RGPIN-2015-03880). The third author's research is partially supported by MINECO under projects ECO201452343-P and ECO2017-82227-P (AEI) and by Junta de Castilla y León VA024P17 and VA105G18 co-financed by FEDER funds (EU).

†Corresponding author 

Associates Report, 2015). Considerable literature has studied the effectiveness of cooperative advertising programs for firms in the supply chain (see reviews by Aust and Buscher (2014) and Jørgensen and Zaccour (2014)). Results in this literature are derived from game-theoretic models where the firms' strategies consist of marketing decisions related to pricing, advertising and promotion. The literature assessed the effects of such programs on the firms' marketing strategies and profits as well as on the supply chain coordination achievements. A common result in this literature is that cooperative advertising programs implemented in bilateral monopolies lead to higher retailer's promotions and advertising expenditures and increased pricing to consumers. In most cases, this combination leads to higher profits for all firms within a chain, although without mimicking the performance of a vertically integrated chain (e.g., Jørgensen et al., 2000; Huang and Li, 2001; Yue et al., 2006; Karray and Zaccour, 2006; Xie and Ai, 2006; Yang et al., 2013; He et al., 2009; Zhang et al., 2013; Martín-Herrán and Sigué, 2017).

The effectiveness of cooperative advertising programs has been analyzed in both the marketing and operations management literature. In marketing, research has focused on modeling advertising decisions in bilateral monopolistic channels (e.g., Huang and Li, 2001; Li et al., 2002; Xie and Ai, 2006) as well as in more complex settings involving several competitive interactions among channel members (Liu et al., 2014; Karray, 2015; Karray et al., 2017). Most of this literature characterizes dynamic games using the goodwill model developed by Nerlove and Arrow (1962) (Jørgensen et al., 2000, 2003; Karray and Zaccour, 2005; He et al., 2009; Zhang et al., 2013). These models assume that advertising subject to cooperative advertising programs impacts the product's brand image (goodwill), which then influences the demand and the whole business model. In the operations management literature, the use of cooperative advertising programs has mostly been disregarded. A few exceptions are noted. For example, De Giovanni (2011) evaluates the effectiveness of a cooperative advertising program within a quality management problem. He considers that for a manufacturer, it is challenging to decide whether to increase business by investing in quality improvements or by supporting the retailer's advertising efforts. De Giovanni and Zaccour (2013) implement a cooperative program within the context of closed-loop supply chain in which firms cooperate on a green program to increase the number of returns and cost savings. Zhang et al. (2013) model a supply chain in which a retailer invests in a preservation technology effort and a manufacturer proposes a cooperative program to improve the economic outcomes of all firms. In the context of service operations, Zha et al. (2015) characterize the case in which firms share the cost when capacity allocation is inefficient. They show the conditions under which a cooperative program leads to coordination (Zha et al., 2015). Cho and Gerchak (2005) compare traditional coordination schemes such as wholesale price and a revenue-sharing contract to a cooperative advertising program based on operating costs. They consider that a manufacturer pays a part of the retailer's operating cost to achieve coordination. Kaya (2010) compares a cooperative advertising program to other coordination mechanisms, in which a manufacturer pays part of the retailer's efforts, which can take several forms. The study shows that a cooperative program can seldom coordinate a chain compared to other more efficient agreements, such as revenue-sharing contracts.

According to the literature we explored, no paper has so far investigated the effect of cooperative advertising programs by also incorporating inventory and production problems. Thus, we contribute to this literature stream by characterizing a game in which a supply chain adopts a cooperative advertising program. Our contribution consists of including both inventory and production decisions (operational issues) along with advertising and pricing decisions (marketing issues). In particular, we consider a supply chain formed by one manufacturer, who sets the production decisions and accumulates inventory at the retailer's store, and 

inventory dynamics developed by Jørgensen (1986) within a VMI policy. The manufacturer directly manages the inventory at the retailer's store, by increasing the stock through production, and the inventory decreases with consumers' purchases.

In our game, we assume that the manufacturer is challenged by producing at a certain rate to reach operational efficiency and to make his product available for the supply chain. In fact, we focus on a brickand-mortar supply chain framework in which consumers can only purchase products that are available on the retailer's store. The latter is a proxy of the market potential as it corresponds to the maximum amount that can be sold in the market. The retailer sets the price and the advertising efforts to increase the sales and decrease the stock of inventory. When a cooperative program is in place, the manufacturer also determines the advertising support to be given to the retailer that would stimulate sales and help control the inventory.

To focus on the effects of cooperative advertising on profits and its effectiveness in coordinating the supply chain, we use a consignment contract according to which the manufacturer supplies the products to be sold to the retailer's store. The retailer sells these products and the two firms share the profits according to a sharing rule negotiated ex-ante and embedded in the consignment contract (De Giovanni, 2016). Thus, all possible internal inefficiencies linked to double marginalization effects are limited by the use of a sharing contract (Cachon and Lariviere, 2005). Consignment contracts with revenue sharing are very popular in supply chain coordination and have been widely applied in many industries including online marketplaces such as Amazon.com (Li and Hua, 2008), electronics (Hung et al., 1995) and fashion (Xiao and Jin, 2011). Under consignment arrangements, the upstream and downstream firms negotiate beforehand a revenuesharing percentage and, accordingly, the upstream firm sets the stocking quantity and/or selling price (Wang et al., 2004; Li and Hua, 2008; Li et al., 2009). Li and Hua (2008) investigate the suitability of a consignment contract with revenue sharing by using several types of demand functions, and find that the mechanism leads to a profit-Pareto-improving situation in most cases. Wang et al. (2004) study the management of a supply chain under a consignment contract with revenue-sharing rules and find that the share levels as well as the demand price elasticity determine the convenience of using such a coordination mechanism. Adida and Ratisoontorn (2011) investigate two types of consignment contracts, one with a revenue-sharing rule and one without. They discover that an upstream firm would select a consignment with revenue sharing only when the downstream firm provides a sufficiently large level of differentiation. The latter, instead, will always prefer a consignment without share. Battini et al. (2010) show the benefits of a consignment contract for single members of a supply chain as well as for the entire chain even when the operational conditions are challenging due to space constraints, obsolescence risks, demand variability and shortage risks. Li et al. (2009) find that a consignment contract with revenue sharing can perfectly coordinate a supply chain when some restrictions are imposed on the demand function. Other papers, such as Dong and Xu (2002) and Cachon (2004), show that the consignment contract cannot perfectly coordinate the decentralized supply chain, thus leaving an open question on its real suitability. Interestingly, none of these papers deals with the use of a cooperative advertising program under a consignment contract with revenue sharing. Thus, we aim to contribute to this research domain by exploring the suitability of a cooperative advertising program within the framework of consignment contracts with production decisions and inventory problems.

Finally, the literature reveals that VMI and consignment contracts with revenue sharing have been investigated jointly, but without considering a cooperative advertising program. For example, Cachon (2004) and Berstein et al. (2006) identify the conditions according to which a consignment contract with a sharing mechanism works well for the entire supply chain under some specific conditions, even in presence of VMI 

be better-off when the vendor installs flexible production capacity leading to lower setup cost, lower lot-size and frequent shipments. Ru and Wang (2010) explore two settings in which the inventory decisions can be taken either by a supplier or by a retailer. They show that the VMI with a consignment contract works better when the supplier takes care of the inventory. Chen (2013) demonstrates that a VMI with a revenue-sharing agreement is beneficial only for a few firms when cooperation is an option. In fact, the retailers can be penalized by such agreements, especially because of their influence on the pricing strategies. None of the papers we have reviewed explores the benefits of a cooperative advertising program within the framework of a VMI policy and a consignment contract, thus leaving a research gap that we aim to fill.

Accordingly, we solve two Stackelberg differential games in which a VMI policy is complemented through a consignment contract with a revenue-sharing rule. In the first game, the manufacturer does not supply any support to the retailer, thus there is no cooperative advertising program in place. This represents our benchmark scenario. In the second game, the manufacturer offers a cooperative advertising program by paying a certain fraction of the retailer's advertising expenses. We analyze the strategies, the profit functions and the inventory policy in the two scenarios and contrast the results to check the suitability of a cooperative advertising program within the aforementioned settings. Our findings reveal that: 1. Contrary to the marketing literature, coordination with a cooperative advertising program is very difficult when supply chains use a VMI with a consignment contract. 2. In accordance with the literature, a cooperative advertising program leads to larger production and advertising efforts and higher prices. 3. Contrary to the literature, the adoption of a cooperative program is seldom profit-Pareto-improving because the manufacturer is highly penalized by a cooperative advertising program. 4. The adoption of a cooperative program makes the inventory almost independent of the consignment contract terms and clauses. 5. When a cooperative program is in place, the retailer invests more in advertising even when the share of revenues that she retains decreases. 6. The manufacturer pushes for the implementation of a cooperative program only when the business is not appealing to him, otherwise he will not cooperate. 7. The retailer may prefer not to cooperate when the share of revenues that the manufacturer receives is too high. Further, we extend our model to incorporate four special cases. We find that: 1 . Under a wholesale price contract, a cooperative program is never feasible. 2. Firms can increase the suitability of a consignment contract with revenue sharing when differentiating between the inventory cost sharing rule and the revenue sharing rule. 3. Firms can better exploit the effectiveness of a cooperative program if inventory obsolescence exists. 4. The suitability of a cooperative program does not depend on the consumers' sensitivity to price and promotion when implementing both VMI and consignment contracts with revenue sharing.

The rest of the paper is organized as follows. Section 2 presents the model and assumptions. Section 3 exposes the feedback equilibrium solutions obtained for the benchmark and for the cooperative advertising games. In Section 4, we analyze the solutions and compare equilibria across games to evaluate the effectiveness of the cooperative advertising program. Section 5 develops some special cases to investigate extensions of the model. Finally, Section 6 concludes and discusses future research avenues.

\section{Model}

Consider a supply chain formed by one manufacturer, $M$, and one retailer, $R$. Both firms make their decisions over an infinite time horizon. At each instant in time, $t, M$ decides on the production rate, $u(t)$, while $R$ makes all marketing decisions, namely, the level of advertising activities, $A(t)$, and pricing to consumers, 
$p(t)$. $M$ can also set a cooperative advertising program to encourage $R$ 's local advertising activities (flyers, displays, etc.). This program consists of sharing the cost of $R$ 's advertising at a rate of $B(t) \in(0,1)$ at instant $t$, where $B(t)$ is a $M$ 's control. All notations are summarized in Table 1.

\begin{tabular}{ll}
\hline$t$ & time, $t \geq 0$ \\
$p(t)$ & Retail price at time $t, p(t) \geq 0$ \\
$A(t)$ & Retailer's advertising efforts at time $t, A(t) \geq 0$ \\
$u(t)$ & Manufacturer's production rate at time $t, u(t) \geq 0$ \\
$B(t)$ & Manufacturer's cooperative advertising rate at time $t, B(t) \in[0,1]$ \\
$D(t)$ & Demand rate at time $t, D(t) \geq 0$ \\
$C_{u}(t)$ & Production cost at time $t, C_{u}(t) \geq 0$ \\
$C_{A}(t)$ & Advertising investments at time $t, C_{A}(t) \geq 0$ \\
$Y(t)$ & Inventory held at the retailer's store at time $t, Y(t)>D(t)$ \\
$Y_{0}$ & Initial inventory level at time $0, Y_{0} \geq 0$ \\
$J_{M}$ & Accumulated profit of the manufacturer \\
$J_{R}$ & Accumulated profit of the retailer \\
$V_{M}$ & Value function of the manufacturer \\
$V_{R}$ & Value function of the retailer \\
$\beta$ & Marginal effect of price on demand parameter, $\beta>0$ \\
$\gamma$ & Marginal effect of advertising on demand parameter, $\gamma>0$ \\
$\phi$ & Sharing parameter, $\phi \in(0,1)$ \\
$c_{R}$ & Marginal inventory holding cost parameter, $c_{R}>0$ \\
$h$ & Marginal production cost parameter, $h>0$ \\
$k$ & Manufacturer's production target parameter, $k>0$ \\
$r$ & Discount rate parameter, $r \in(0,1)$ \\
$M$ & Manufacturer \\
$R$ & Retailer
\end{tabular}

Table 1. List of notations

We assume that the demand rate takes the following form:

$$
D(Y(t), p(t), A(t))=Y(t)-\beta p(t)+\gamma A(t) .
$$

At each instant in time, $t$, the demand rate is a linear function of the price, $p(t)$, and $R$ 's advertising efforts, $A(t)$ (e.g., Jørgensen et al., 2000; De Giovanni, 2011). Further, this formulation assumes that $R$ does not permit shortages (no stockout), meaning she can sell at most the goods available in stock at a specific time, $t$, which is given by the positive inventory level, $Y(t)$. This is very common in brick-and-mortar retail stores, where stockouts occur whenever demand exceeds the level of inventory available at the retail location. We assume that $Y(t) \geq D(t)$ as well as that the delivery lead time is null, meaning that orders are delivered immediately. In this set-up, the inventory $Y(t)$ is a proxy for the market potential.

Demand is positively influenced by $R$ 's advertising activities (e.g., displays and features), and the marginal effect of advertising on demand is represented by the positive parameter $\gamma$. As is common in the economics literature, prices are negatively related to demand, with a unit increase in price leading to lower demand. The marginal effect of price on demand is modeled through the positive parameter $\beta$.

At each instant in time, the inventory level, $Y(t)$, is increased by the number of units produced by $M$, $u(t)$, and is reduced by the units sold to consumers, $D(t)$. Following Jørgensen (1986) and Erickson (2012) 
the dynamic evolution of $Y(t)$ over time, $\dot{Y}(t)$, given an initial inventory at time zero of $Y_{0}$, can be written as follows:

$$
\dot{Y}(t)=u(t)-D(t), \quad Y(0)=Y_{0} .
$$

To focus on the profitability of cooperative advertising programs without dealing with changes in the other decisions arising from the opportunistic behaviors of firms, we assume that $M$ and $R$ coordinate their inventory and pricing decisions. In particular, $M$ manages inventory on behalf of $R$ according to a Vendor Management Inventory (VMI) system (Ben-Daya et al., 2013; Chen, 2013; Ru and Wang, 2010). $M$ and $R$ have agreed on and implemented a cost-sharing contract by which $M$ pays for a portion of the inventory holding costs and $R$ pays for the remaining cost. Consider a total inventory cost of $c_{R} Y(t)$ for the supply chain, where $c_{R}>0$ is the marginal inventory cost at the $R$ 's store. Therefore, $M$ 's share in the inventory cost is given by $\phi c_{R} Y(t)$ while $R$ pays $(1-\phi) c_{R} Y(t)$. The parameter $\phi \in(0,1)$ is the sharing parameter, according to which firms share both costs and profits.

In such a coordinated supply chain, it is in the best interest of both firms to reduce the inventory, $Y(t)$, as much as possible. Also, the VMI protects $R$ from aggressive production levels by an opportunistic manufacturer seeking production cost savings from economies of scale. It also pushes $R$ to adopt a proper marketing policy to increase inventory turnover. To our knowledge, this is the first paper that accounts for both dynamic inventory, production rate, pricing and advertising strategies to study cooperative advertising programs.

We assume that the firms' collaboration also extends to price coordination via a consignment contract with a revenue-sharing agreement ( $\mathrm{Li}$ and Hua, 2008; Li et al., 2009; Adida and Ratisoontorn, 2011). In particular, $M$ does not charge a wholesale price to $R$ who can set the product price, $p(t)$, without suffering from $M$ 's marginalization. As a result, the supply chain members eliminate inefficiencies arising from double marginalization issues. For simplicity, we assume that the same sharing terms for inventory costs are used to share the marginal revenue, $p(t)$. Hence, for each unit sold, $M$ earns, $\phi p(t)$, and $R$ pockets the remaining unit margin, $(1-\phi) p(t)$. In this set-up, $\phi$ is given, meaning that $M$ and $R$ are engaged in a long-term commitment to share their inventory costs and revenues.

Finally, we assume that the costs of advertising $\left(C_{A}(t)\right)$ and of production $\left(C_{u}(t)\right)$ take standard convex forms to represent increasing marginal costs (Karray, 2015; He et al., 2009; El Ouardighi et al., 2008). In particular, the production cost function at each time $t$ takes the following form:

$$
C_{u}(u(t))=\frac{h(u(t)-k)^{2}}{2} .
$$

$M$ pays for the cost of producing the product at a marginal cost, $h>0$, with a production target $k>0$ (El Ouardighi et al., 2008). The parameter $k$ represents the efficient production quantity. $M$ 's production costs are minimized when its production rate is close to $k$, while any production rate that is lower or higher than the efficient quantity $k$ results in higher costs. The advertising cost $\left(C_{A}\right)$ at each time $t$ is given by

$$
C_{A}(t)=\frac{A(t)^{2}}{2} .
$$

In the case where a cooperative advertising program is implemented in the channel $(B(t) \neq 0)$, firms' profit functions are the sum of their discounted profits over time (at a discount rate $r \in(0,1)$ ). They are 
represented by $J_{M}$ and $J_{R}$, respectively, and the firms' objective functions are given by:

$$
\begin{aligned}
J_{M} & =\int_{0}^{+\infty} e^{-r t}\left\{D(t) p(t) \phi-\frac{h(u(t)-k)^{2}}{2}-\frac{B(t)}{2}(A(t))^{2}-c_{R} \phi Y(t)\right\} d t, \\
J_{R} & =\int_{0}^{+\infty} e^{-r t}\left\{D(t) p(t)(1-\phi)-\frac{(1-B(t))}{2}(A(t))^{2}-c_{R}(1-\phi) Y(t)\right\} d t .
\end{aligned}
$$

When the firms do not implement a cooperative advertising program, the cooperative advertising rate takes a null value $(B(t)=0)$ and is not a choice variable for $M$ 's problem. $M$ 's profit margin is represented by his share in the marginal revenue diminished by a portion of the inventory costs $\left(\phi c_{R} Y(t)\right)$. Whenever the cooperative advertising program is implemented, $M$ pays a portion of $R$ 's advertising costs at a rate of $B(t)$. Similarly, $R$ 's profits are formed by her share in revenues diminished by her share in the advertising costs, whenever a cooperative advertising is implemented, and by her share in the inventory costs.

Further, we assume that $M$ acts as a Stackelberg leader. The marketing and managerial decisions will be determined as feedback strategies. Because the game is played over an infinite time horizon with timeindependent parameters, we focus on stationary equilibrium strategies. Using stationary feedback strategies means that the manufacturer conditions his decisions at time $t$ upon the current level of inventory. That is the decisions of the supply chain are functions of the current level of the inventory (the state variable), $Y$.

In a Stackelberg game $M$, as the first mover (leader) announces his production rate $(u)$ and support of $R$ 's advertising costs $(B)$. This information is taken into account by $R$ (follower) who chooses the price to consumers $(p(Y))$ and the level of her advertising efforts $(A(Y))$. Once the information about these later decisions is made available to $M$, he decides about his actual production rate $(u(Y))$ and advertising support $(B(Y))$. The following table summarizes the three steps previously described. This sequence of play is based on the observation that manufacturers usually initiate cooperative advertising programs. In fact, according to a survey conducted by the National Register Publishing, manufacturers announce their cooperative advertising rates before retailers decide on their advertising. ${ }^{1}$ This sequence is also based on the managerial practice of deciding on production levels after checking (observing) the available inventory levels.

\begin{tabular}{ll}
$1^{\text {st }}$ step & $M$ announces $u$ and $B$ \\
$2^{\text {nd }}$ step & $R$ chooses $p$ and $A$ \\
$3^{r d}$ step & $M$ chooses $u$ and $B$ \\
\hline
\end{tabular}

Table 2. Sequence of play in the Stackelberg game ( $M$ as leader and $R$ as follower)

\section{Equilibrium solutions}

We solve the dynamic optimization problems and obtain the equilibrium solutions for both the benchmark and the cooperative advertising games. As for all conventional solutions in dynamic games with infinite time horizon, all strategies and value functions will be written exclusively as functions of the state variable.

\footnotetext{
${ }^{1}$ See Co-opadvertisingprograms.com, the on-line database of NRP for coop advertising programs (http://www.coopsourcebook.com/coop_sample.htm).
} 


\subsection{The Benchmark scenario (no cooperative advertising)}

We start by solving the benchmark (non-cooperative) game, denoted by $N$, in which a cooperative advertising program is not implemented. In this setting, $M$ focuses on the operational strategies, namely, the production rate, $u^{N}(Y)$, and $R$ sets the marketing strategies, namely, the price $p^{N}(Y)$ and the advertising efforts $A^{N}(Y)$. All these strategies contribute to the dynamic evolution of the inventory, and hence, determine its optimal path $Y^{N}(t)$. The game evolves according to the following moves. $M$ announces the feedback production rate without cooperative program, $u(Y) . \quad R$ (the follower) reacts rationally to the leader's announcement and sets the pricing and advertising strategies, $p^{N}(Y \mid u(Y))$ and $A^{N}(Y \mid u(Y))$ to optimally respond to the $M$ 's announcement. $M$ takes $R$ 's best-replies into consideration and solves his problem by optimally setting $u(Y)$. The solution to the benchmark game yields the equilibrium feedback strategy $u^{N}(Y)$ for $M$. Once we have it, we can write $R$ 's feedback pricing and advertising strategies, $p^{N}(Y)=$ $p^{N}\left(Y \mid u^{N}(Y)\right)$ and $A^{N}(Y)=A^{N}\left(Y \mid u^{N}(Y)\right)$. The strategies $u^{N}(Y), p^{N}(Y)$ and $A^{N}(Y)$ constitute the Stackelberg feedback solution for the benchmark case. By using these strategies in Eq. (2) and solving the differential equation, the optimal time-path for the inventory level is given by $Y^{N}(t)$, for all $t \geq 0$.

Proposition 1 The equilibrium strategies in the benchmark scenario (no cooperative advertising) are given by:

$$
\begin{aligned}
u^{N}(Y) & =\frac{M_{1}^{N} Y+M_{2}+h k}{h} \\
A^{N}(Y) & =\frac{\gamma\left(Y\left(1-\phi-\beta R_{1}^{N}\right)-\beta R_{2}^{N}\right)}{2 \beta-\gamma^{2}(1-\phi)} \\
p^{N}(Y) & =\frac{Y(1-\phi)+\left(R_{1}^{N} Y+R_{2}^{N}\right)\left(\beta-\gamma^{2}(1-\phi)\right)}{(1-\phi)\left(2 \beta-\gamma^{2}(1-\phi)\right)}
\end{aligned}
$$

where $M_{i}^{N}, R_{i}^{N}, i=1, \ldots, 3$ are the coefficients of the value functions $V_{M}^{N}(Y)$ and $V_{R}^{N}(Y)$ given by

$$
\begin{aligned}
& V_{M}^{N}(Y)=M_{1}^{N} \frac{(Y)^{2}}{2}+M_{2}^{N} Y+M_{3}^{N}, \\
& V_{R}^{N}(Y)=R_{1}^{N} \frac{(Y)^{2}}{2}+R_{2}^{N} Y+R_{3}^{N} .
\end{aligned}
$$

These coefficients depend on the model's parameters and the value functions describe the optimal profits along the whole optimal inventory trajectory $\left(Y^{N}(t)\right.$.

The optimal time-path of the inventory reads:

$$
Y^{N}(t)=\left(Y_{0}-Y_{S S}^{N}\right) e^{\left(M_{1}^{N}-h K_{4}\left(1-\phi-\beta R_{1}^{N}\right)\right) t}+Y_{S S}^{N},
$$

where

$$
Y_{S S}^{N}=\frac{h\left(\beta K_{4} R_{2}^{N}+k\right)+M_{2}^{N}}{h K_{4}\left(1-\phi-\beta R_{1}^{N}\right)-M_{1}^{N}},
$$

is the steady-state inventory level. This steady state is globally asymptotically stable if and only if $M_{1}^{N}-$ $h K_{4}\left(1-\phi-\beta R_{1}^{N}\right)<0$, where constant $K_{4}$ is given in Appendix A.

Proof. See the online Appendix.

Although we characterize the equilibrium solutions analytically, the expressions of strategies, demand and payoffs depend heavily on all parameter values, thus precluding any analytical insight. We resort to a 
numerical analysis of these expressions in Section 4, to derive some strategic insights and answer our research questions.

\subsection{The cooperative advertising scenario}

In the cooperative advertising scenario, denoted by $C, M$ offers a cooperative advertising program to $R$. In

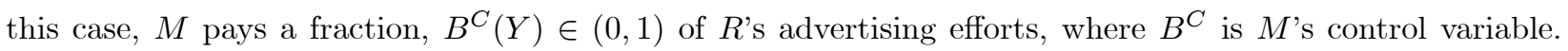
Hence, the firms share the advertising cost, in addition to coordinating their pricing and inventory decisions. Following the same lines as in the non-cooperative scenario, in this setting, $M$ announces the feedback production rate, $u(Y)$, and his cooperative advertising rate, $B(Y)$, and $R$ reacts to this announcement and sets her optimal best responses for the price and the advertising efforts. The manufacturer takes into account the retailer's best-response functions and optimally sets $u^{C}(Y)$ and $B^{C}(Y)$. The retailer's optimal strategies $p^{C}(Y)$ and $A^{C}(Y)$ are obtained by injecting the manufacturer's equilibrium decisions into the retailer's bestresponse functions. These optimal strategies are then used in Eqs. (1) and (2). Solving the differential equation in (2), we get the optimal time-path for the inventory level, $Y^{C}(t)$, for all $t \geq 0$. The equilibrium solution is provided in the next proposition.

Proposition 2 The equilibrium strategies and profits in the cooperative advertising scenario are given by:

$$
\begin{aligned}
u^{C}(Y) & =\frac{M_{1}^{C} Y+M_{2}^{C}+h k}{h}, \\
A^{C}(Y) & =\frac{\gamma\left(Y(1+\phi)-2 \beta\left(M_{1}^{C} Y+M_{2}^{C}\right)-\beta\left(R_{1}^{C} Y+R_{2}^{C}\right)\right)}{2\left(2 \beta-\gamma^{2}\right)}, \\
p^{C}(Y) & =\frac{Y L_{1}-\left(M_{1}^{C} Y+M_{2}^{C}\right) L_{2}+\left(R_{1}^{C} Y+R_{2}^{C}\right) L_{7}}{4 \beta\left(2 \beta-\gamma^{2}\right)(1-\phi)}, \\
B^{C}(Y) & =\frac{Y \Delta-2 \beta M_{2}^{C}\left(2 \beta-\gamma^{2}(1-\phi)\right)+\beta R_{2}^{C}\left(2 \beta-\gamma^{2}(1+\phi)\right)}{2 \beta\left(Y(1+\phi)-2 \beta\left(M_{1}^{C} Y+M_{2}^{C}\right)-\beta\left(R_{1}^{C} Y+R_{2}^{C}\right)\right)},
\end{aligned}
$$

where constants $\Delta$ and $L_{i}, i=1, \ldots, 7$ are given in Appendix $B . M_{i}^{C}, R_{i}^{C}(i=1, \ldots, 3)$ are the coefficients of the firms' value functions, which are given by

$$
\begin{aligned}
V_{M}^{C}(Y) & =M_{1}^{C} \frac{(Y)^{2}}{2}+M_{2}^{C} Y+M_{3}^{C}, \\
V_{R}^{C}(Y) & =R_{1}^{C} \frac{(Y)^{2}}{2}+R_{2}^{C} Y+R_{3}^{C} .
\end{aligned}
$$

These coefficients depend on the model's parameters and the value functions describe the optimal profits along the whole optimal inventory trajectory $\left(Y^{C}(t)\right)$.

The optimal time-path of the inventory reads:

$$
Y^{C}(t)=\left(Y_{0}-Y_{S S}^{C}\right) e^{\frac{1}{h}\left(M_{1}^{C}-L_{5}\left(L_{1}-M_{1}^{C} L_{2}-R_{1}^{C} L_{3}\right)\right) t}+Y_{S S}^{C},
$$

where

$$
Y_{S S}^{C}=\frac{M_{2}^{C}+h k+L_{5}\left(M_{2}^{C} L_{2}+R_{2}^{C} L_{3}\right)}{L_{5}\left(L_{1}-M_{1}^{C} L_{2}-R_{1}^{C} L_{3}\right)-M_{1}^{C}},
$$

is the steady-state inventory level. This steady state is globally asymptotically stable if and only if $M_{1}^{C}-$ $L_{5}\left(L_{1}-M_{1}^{C} L_{2}-R_{1}^{C} L_{3}\right)<0$. 


\section{Proof. See the online Appendix.}

As in the benchmark scenario, the expressions (13) - (16) show that all strategies in the cooperative advertising scenario are state-dependent. In particular, the cooperative advertising support rate also depends on the inventory level held in the channel. Therefore, contrary to previous studies that ignored the effects of inventory on advertising and on operational decisions in the supply chain, this finding reveals that both $M$ 's support rate and $R$ 's advertising decisions should be adjusted to changes in the level of inventory held in the channel. As for the benchmark case, the complexity of the equilibrium solution precludes any analytical development and imposes the requirement that we proceed numerically to shed light into the research contributions and findings.

\section{Numerical analysis}

Due to the complexity of our model in each game, the parameter values obtained from solving the Riccati's systems of equations are heavily coupled, which preclude any analytical analysis. Thus, we resort to numerical methods to obtain and illustrate our results.

First, we fix the parameter values as follows:

$$
\phi=0.27, \beta=2, \gamma=1.5, c_{R}=1.5, r=0.4, h=5, k=5 .
$$

These parameter values have been chosen for two reasons. First, similar values have been used in the literature (El Ouardighi et al., 2008; De Giovanni, 2011). Second, these values guarantee that the feasible region for both games have common parameter values. A feasible domain corresponding to the equilibrium solution in a game is defined as the set of parameter values for which the equilibrium decision variables, demands and profits are positive and the concavity conditions for the players' problems are verified. In the online Appendix, we display the feasibility analysis for parameters $\phi, \beta$ and $\gamma$. We run many more simulations to identify the feasible region using the other parameters $c_{R}, r$ and $h$. For brevity, we do not display the full feasibility region analysis. However, these simulations are available from the authors upon request.

Because the planning horizon is infinite, we focus on steady-state strategies and payoffs. After fixing the benchmark parameter values, we characterize the behavior of the different variables and payoffs at the steady state (Sections 4.1 and 4.2). Then, we focus on the analysis of the sharing rate parameter (Section 4.3) to identify the region in which a cooperative program is an efficient mechanism, and investigate how strategies and state change accordingly.

\subsection{Steady-State analysis in the $N-$ Scenario}

All expressions in the benchmark solution are state-dependent and, along with the state, are heavily dependent on the constants $M_{i}^{N}, R_{i}^{N}, i=1,2,3$. The latter expressions can only be identified numerically because the Riccati's equations to determine $M_{1}^{N}, R_{1}^{N}$ are heavily coupled (see Appendix A). In particular, we obtain four roots when solving the system of Riccati equations $M_{i}^{N}, R_{i}^{N}$, two of which are imaginary and two are real. Between the two real roots, only one satisfies all of the model's assumptions, specifically positive strategies, demand, inventory and profits at the steady state. By using the benchmark parameter values, the "good" root gives: $M_{1}^{N}=0.0849, M_{2}^{N}=0.0408, M_{3}^{N}=0.4591, R_{1}^{N}=0.1914, R_{2}^{N}=-0.1735, R_{3}^{N}=-2.0851$. Accordingly, the strategies, sales, state and profits take the following values: $Y_{S S}^{N}=11.9135, u_{S S}^{N}=D_{S S}^{N}=$ $5.2106, A_{S S}^{N}=2.8528, p_{S S}^{N}=5.491, V_{M_{S S}}^{N}=6.973, V_{R_{S S}}^{N}=9.4297$. 
Note that the model we propose in this research does not allow for zero inventory, which is instead a target in the operations management literature (e.g., Chen, 2013). This links to our model assumptions, as $Y_{S S}^{N}$ cannot be null and $Y_{S S}^{N}>D_{S S}^{N}$. This is also in line with our framework according to which consumers turn away in case of exhausted inventory. Thus, both firms have an incentive to adjust that stock at a proper level. Specifically, when the inventory is very low at the beginning of an ideal planning horizon, firms will adjust their strategies to reach the inventory at the steady-state level. In contrast, when the initial stock is too high, the firms' strategies will be set to decrease the stock at the steady-state level.

Results 1 At the steady state, the following results apply:

- $u_{S S}^{N}$ and $D_{S S}^{N}$ increase with $Y_{S S}^{N}$, as $\frac{\partial u_{S S}^{N}}{\partial Y_{S S}^{N}}=\frac{M_{1}^{N}}{h}>0$

- $p_{S S}^{N}$ increases with $Y_{S S}^{N}$, as $\frac{\partial p_{S S}^{N}}{\partial Y_{S S}^{N}}=\frac{1-\phi+\left(\beta-\gamma^{2}(1-\phi)\right) R_{1}^{N}}{(1-\phi)\left(2 \beta-\gamma^{2}(1-\phi)\right)}>0$;

- $A_{S S}^{N}$ increases with $Y_{S S}^{N}$ as $\frac{\partial A_{S S}^{N}}{\partial Y_{S S}^{N}}=\frac{\gamma\left(1-\phi-\beta R_{1}^{N}\right)}{2 \beta-\gamma^{2}(1-\phi)}>0$;

- $V_{M_{S S}}^{N}$ increases with $Y_{S S}^{N}$ as $\frac{\partial V_{M_{S S}}^{N}}{\partial Y_{S S}^{N}}=M_{1}^{N} Y_{S S}^{N}+M_{2}^{N}>0$;

- $V_{R_{S S}}^{N}$ increases with $Y_{S S}^{N}$ as $\frac{\partial V_{R_{S S}}^{N}}{\partial Y_{S S}^{N}}=R_{1}^{N} Y_{S S}^{N}+R_{2}^{N}>0$.

The conventional inventory models in the literature suggest that the presence of a large stock leads a firm to produce less (e.g., El Ouardighi et al., 2008; Chen, 2013). In contrast, our result indicates that production rates increase with higher inventory levels. This is due to the role played by the inventory, which also determines the market potential and then the sales development. Furthermore, the dynamic inventory policy is set according to a VMI policy rather than by using a make-to-stock approach, as in Jørgensen (1986), Kogan and Tapiero (2007) and Erikson (2012). $M$ expands his business when producing high quantities. Interestingly, $M$ solves the trade-off between increasing holding cost versus increasing demand by favoring sales growth. Thus, under a VMI policy, the production rate becomes a marketing device to boost sales rather than efficiently reducing the inventory cost. Because large inventory expands the market potential, $R$ can charge a higher price while ensuring that demand will not suffer from it. This result also depends on larger advertising efforts induced by higher accumulated inventory. Overall, the pricing and advertising strategies complement each other to guarantee optimized sales and profits. Intuitively, the presence of large stock leads $R$ to advertise more, with the final target to reduce the inventory and increase sales. This finding depends on the structure of the VMI policy, according to which $M$ manages $R$ 's inventory. So, $M$ seeks to increase the inventory as much as possible. Finally, having a wider reference-display obtained by keeping high stocks of inventory translates into larger profits for $M$. Consequently, there is a need to investigate the conditions as well as the most relevant parameters to assess a VMI policy. Finally, R's profits increase with the stock of inventory. Although the larger advertising efforts required to sell off the inventory in stock harm $R$ 's profits, $M$ 's contribution to pay the holding cost makes large values of $Y$ profitable for $R$ as well.

\subsection{Steady-State analysis in the $C-$ Scenario}

As in the benchmark scenario, Eqs. (13) - (16) show that all strategies are state-dependent. Thus, regardless of the stage of the game, each player observes the level of inventory before setting their strategies. This is consistent with a support program in supply chains and marketing channels, in which a firm decides to support the advertising efforts of a partner to contribute more to the overall business. As for the benchmark 
scenario, the Riccati's equations to determine the parameters $M_{i}^{C}, R_{i}^{C}, i=1,2,3$ are heavily coupled (see Appendix B) and their values can only be determined by following the same computational procedure as in the $N$ - scenario. By using the benchmark parameter values, we then obtain two imaginary and two real roots. Among the real roots, only one satisfies all of the model's assumptions. The "good" root for the cooperative game gives: $M_{1}^{C}=0.0848, M_{2}^{C}=0.0393, M_{3}^{C}=0.4529, R_{1}^{C}=0.1930, R_{2}^{C}=-0.1745, R_{3}^{C}=-2.1192$. Accordingly, the strategies, sales, state, and profits take the following steady-state values: $Y_{S S}^{C}=11.9549$, $u_{S S}^{C}=D_{S S}^{C}=5.2107, A_{S S}^{C}=2.8729, p_{S S}^{C}=5.5268, V_{M_{S S}}^{C}=6.9851, V_{R_{S S}}^{C}=9.5856, B_{S S}^{C}=0.0070$.

Consistent with the results in the benchmark scenario, there exists only one solution that satisfies the positivity assumptions on strategies, demand, inventory and profits, and should then be used to assess the cooperative scenario.

Results 2 At the steady state, the following results apply:

- $u_{S S}^{C}$ and $D_{S S}^{C}$ increase with $Y_{S S}^{C}$ as $\frac{\partial u_{S S}^{C}}{\partial Y_{S S}^{C}}=\frac{M_{1}^{C}}{h}>0$;

- $p_{S S}^{C}$ increases with $Y_{S S}^{C}$ as $\frac{\partial p_{S S}^{C}}{\partial Y_{S S}^{C}}=\frac{L_{1}-M_{1}^{C} L_{2}+R_{1}^{C} L_{7}}{4 \beta\left(2 \beta-\gamma^{2}\right)(1-\phi)}>0$;

- $A_{S S}^{C}$ increases with $Y_{S S}^{C}$ as $\frac{\partial A_{S S}^{C}}{\partial Y_{S S}^{C}}=\frac{\left((1+\phi)-\beta\left(2 M_{1}^{C}+R_{1}^{C}\right)\right) \gamma}{2\left(2 \beta-\gamma^{2}\right)}>0$;

- $B_{S S}^{C}$ increases with $Y_{S S}^{C}$ as $\frac{\partial B_{S S}^{C}}{\partial Y_{S S}^{C}}=-\frac{2\left(2 \beta-\gamma^{2}\right)\left[R_{2}^{C}\left(\phi-\beta M_{1}^{C}\right)+M_{2}^{C}\left(\phi-1+\beta R_{1}^{C}\right)\right]}{\left(\left(2 M_{2}^{C}+R_{2}^{C}\right) \beta+\left(\left(2 M_{1}^{C}+R_{1}^{C}\right) \beta-(1+\phi)\right) Y_{S S}^{C}\right)^{2}}>0$;

- $V_{M_{S S}}^{C}$ increases with $Y_{S S}^{C}$ if and only if $\frac{\partial V_{M_{S S}}^{C}}{\partial Y_{S S}}=M_{1}^{C} Y_{S S}^{C}+M_{2}^{C}>0$;

- $V_{R_{S S}}^{C}$ increases with $Y_{S S}^{C}$ as $\frac{\partial V_{R_{S S}}^{C}}{\partial Y_{S S}}=R_{1}^{C} Y_{S S}^{C}+R_{2}^{C}>0$.

While the steady-state production rate, advertising and price all change in the state as in the benchmark scenario, a new insight emerges from the cooperative scenario regarding the support program, $B_{S S}^{C}$, which increases with the inventory. This result can be explained by the dual role of inventory held at $R$ 's level. Inventory is a proxy for market potential, representing the maximum number of products that can be demanded from the market. So, when $Y_{S S}^{C}$ is large, the market potential is high, and $R$ exerts higher willingness to invest in advertising efforts because of the support program. The latter increases according to the stock of inventory, thus highlighting the idea that firms use the cooperative program parsimoniously and according to the inventory policy put in place.

\subsection{Comparison between the cooperative and non-cooperative games}

After the analysis at the steady-state, we now fix the benchmark parameter values and focus on analyzing the effects of the sharing parameter, $\phi$. In doing that, we seek to identify the region in which a cooperative program is an efficient mechanism and investigate how strategies, demand, inventory and profits change accordingly.

We solve the system of Riccati's equations for each scenario with $\phi$ in $(0.265,0.325)$ with a marginal change of 0.05 . Then, we solve the games 25 times and evaluate the corresponding results at the steady state. We supply a sensitivity analysis in an online Appendix to demonstrate the robustness of our findings. 

and the sharing parameter, $\phi$. This result is quite intuitive and depends on the cooperative structure of the game. The greater (smaller) is M's fraction of revenues, the larger (lower) his support will be. Intuitively, increasing the sharing parameter makes the implementation of a cooperative program more appealing for $M$, who is willing to pay a larger fraction of $R$ 's advertising efforts.

$$
<<\text { Insert Figure } 1 \text { here }>>
$$

As displayed in Figure 2, the presence of a cooperative program substantially influences $R$ 's advertising decision. First, for all values of the sharing parameter, advertising in the cooperative scenario $\left(A_{S S}^{C}\right)$ is higher than that in the non-cooperative scenario $\left(A_{S S}^{N}\right)$, meaning that cooperative advertising leads to higher investments in advertising. This is consistent with the literature about cooperative advertising programs (Jørgensen and Zaccour, 2014). Second, the effect of the sharing parameter on advertising is reversed when a cooperative advertising program is implemented. In fact, $A_{S S}^{N}$ takes lower values as $\phi$ increases, while $A_{S S}^{N}$ increases with higher values of $\phi$. Intuitively, when a cooperative program is not on the menu, $R$ sets the advertising efforts according to the sharing parameter amplitudes. Therefore, the higher (lower) the share, the lower (higher) the advertising efforts. Put differently, when the overall business is marginally economically important for $R$ (e.g., high $\phi$ ), her willingness to contribute to business development through advertising declines. In contrast, the implementation of a cooperative program encourages $R$ to do more even when the share is marginal. $R$ knows that the large sharing parameter values are of considerable interest to $M$, who positively reacts by fixing very high participation rates (see Figure 1). Thus, she invests more in advertising efforts given that $M$ will take care of a part of these investments.

$$
<<\text { Insert Figure } 2 \text { here }>>
$$

In Figure 3, we obtain the prices in the cooperative advertising $\left(p_{S S}^{C}\right)$ and the benchmark $\left(p_{S S}^{N}\right)$ scenarios at the steady state as functions of the sharing parameter. Comparison of these prices shows that the implementation of the cooperative advertising program leads to a higher retail price. This result is in line with the generally accepted finding in the literature, according to which cooperative advertising expands demand through increased advertising expenditure, which allows the retailer to then charge a higher price for the manufacturer's product (e.g., Jørgensen and Zaccour, 2014; He et al., 2009; De Giovanni, 2011).

The role of both advertising efforts and inventory becomes crucial in this sense. Thanks to their effects, $R$ charges a higher price under a cooperative program without losing sales (see our earlier discussion). Interestingly, the price increases with the sharing parameter in both scenarios. This trend has a strategic meaning. When the sharing parameter is low, $R$ gets the largest portion of the entire business. Consequently, a low price ensures a high economic reward for $R$. When the sharing parameter is high, $R$ sets a high price to make $M$ economically worse off. Note that the slope at which the price increases with $\phi$ is higher when firms do not cooperate.

$$
<<\text { Insert Figure } 3 \text { here }>>
$$

Figure 4 displays the changes in both demand and the production rate according to the sharing parameter in the two scenarios. Remember that the production rate and demand are equal at the steady state due to the particular form of the state equation (Eq.(2)). Intuitively, the larger the proportion of revenues $M$ gets, 
the greater will be his production involvement. Hereby, $M$ solves the trade-off between marginal revenues and lower production cost in favor of the former. Specifically, any time the supply chain negotiation outcome grants a larger share to $M$, the production rate substantially moves away from the operational efficiency benchmark, $k$. Indeed, $M$ is also responsible for the inventory at $R$ 's store and for the market potential amplitude. Thus, the more appealing the business becomes for $M$ (large $\phi$ ), the more he will be involved in business development through production. A cooperative program has a positive effect on $M$ 's production decisions. Because $M$ influences inventory turnover through supporting $R$ 's advertising efforts, he produces a lower amount for any given sharing parameter value, decreasing de facto the sales in the cooperative scenario. This depends on the higher price charged to consumers, thus $M$ produces and sells a lower amount at a higher price when supporting $R$ 's advertising efforts. The adoption of a cooperative program allows $M$ to be more operationally efficient as the production rate does not move too far away from the target, $k$. Overall, a cooperative program allows $M$ to better control the inventory by controlling his production, pricing and advertising support.

$$
<<\text { Insert Figure } 4 \text { here }>>
$$

\subsubsection{The effects of the sharing parameter on inventory}

Figure 5 displays the relationship between inventory and the sharing parameter in the two scenarios analyzed. When $M$ 's share is low, he has less willingness to produce within this business, thus low inventory leads to low production rate and, consequently, to a low market potential. When $M$ gets a larger share, he produces more and accumulates larger stock of inventory. In such cases, inventory is always larger than the production rate and the demand. Interestingly, there is a parameter region for $\phi$ in which the steady-state inventory without a cooperative program is larger than the steady-state inventory under a cooperative program. In fact, increasing sharing parameter values incentivizes $R$ to advertise more, thus increasing inventory turnover. Intuitively, when stock at the steady state is large, $R$ 's advertises more to attract more consumers and reduce that stock. Further, the adoption of a cooperative program mainly stabilizes the inventory policy that is quite insensitive to changes in the sharing parameter. Thus, a cooperative program on advertising efforts is highly efficient as it decreases the amount of inventory in the supply chain and this effect is quasi sharing parameter independent, meaning that the inventory (and its related costs) will be considerably lowered with the presence of a cooperative program.

\section{$<<$ Insert Figure 5 here $>>$}

\subsubsection{The effects of the sharing parameter on profits}

Figure 6 shows $M$ 's profits changes according to the sharing parameter in both scenarios. When firms do not implement a cooperative program, $M$ would lead the negotiation to the largest possible sharing parameter value. Numerically, one can check that $\frac{\partial V_{M_{S S}}^{C}}{\partial \phi}>0$ always holds for all the sharing parameter values that we analyzed. Regarding the cooperative scenario, the negotiation between firms must lead to a sufficiently large sharing parameter through which the cooperative solution becomes feasible. According to the baseline parameters, this sharing parameter value corresponds to $\underline{\phi}=0.265$, where the lower-bound signifies that this is the minimum sharing parameter value that guarantees a feasible solution for the cooperative game. For $\phi>\underline{\phi}$, it always results that $\frac{\partial V_{M}^{C}}{\partial \phi}>0$ within the range of $\phi$ that we analyzed. Nevertheless, there is only a small region of parameters inside which $M$ is better off through a cooperative program. In particular, $V_{M_{S S}}^{C}-V_{M_{S S}}^{N}>0 \Leftrightarrow \phi \in(\underline{\phi}, \bar{\phi})$. From Figure 6 , one can notice that $\bar{\phi}$ represents the sharing parameter 
value that makes $M$ indifferent between cooperating and non-cooperating. For $\phi>\bar{\phi}, M$ would prefer not to cooperate.

This finding is novel within the literature of supply chain and distribution channel coordination that sponsors the adoption of a cooperative program. When the supply chain implements a VMI policy complemented by a consignment contract with revenue sharing, cooperative advertising is a difficult program with which to achieve better performance. This can be due to different motivations. First, $R$ 's advertising efforts increase with the sharing parameter, thus supporting larger advertising investments that can be detrimental for $M$ 's profits. Second, pricing strategies tend to converge in the sharing parameter values, thus the stronger the coordination, the lower the capability to extract more value from the market. For example, the literature shows that when a support program exists, firms are able to set higher prices without losing sales due to the benefits provided by these mechanisms (e.g., Karray and Zaccour, 2006; Karray, 2013; Martín-Herrán and Sigué, 2017). Interestingly, our findings do not confirm this conclusion. Third, $M$ produces less under a cooperative program, given that he needs to spend some effort to support the advertising investments. This directly leads to lower demand and profits. Finally, a cooperative program stops being convenient when $V_{M_{S S}}^{N}$ is larger than $V_{M_{S S}}^{C}$ under a cooperative program, that is when $\phi>\bar{\phi}$. Indeed, because the inventory links to the store display and product availability, it represents a proxy of market potential that has a considerable impact on $M$ 's profits. Thus, since $M$ is the leader of the chain, he will always look at the nature and the value of $\phi$, then he will announces a wish to implement a support program and play cooperatively.

Therefore, depending on the value of the sharing parameter, $\phi, M$ chooses one of the following three contractual options:

1. When $\phi<0.2675$, only the non-cooperative scenario is feasible, thus $M$ will always avoid cooperative advertising.

2. When $0.2675<\phi \leq \bar{\phi}, M$ will support the $R$ 's advertising efforts and offer a cooperative advertising program.

3. When $\phi>\bar{\phi}, M$ will avoid cooperative advertising as it leads to lower sales due to high prices.

$$
<<\text { Insert Figure } 6 \text { here }>>
$$

As displayed in Figure 7, the patterns of $R$ 's profits follow the opposite patterns of $M$ 's profits in both scenarios. $R$ 's profits have a decreasing behavior with respect to the sharing parameter; numerically, one can show that $\frac{\partial V_{R_{S S}}^{N}}{\partial \phi}<0$ and $\frac{\partial V_{R_{S S}}^{C}}{\partial \phi}<0$ for the range of values of the sharing parameter $\phi$ we analyzed. During the negotiation phase, $R$ would design the contract parameters and clauses accordingly.

It results that $V_{R_{S S}}^{C}>V_{R_{S S}}^{N}$ for $\phi$ in the range of interest. Thus, $R$ always prefers the implementation of a cooperative program. This is in line with the general accepted result in the marketing literature, according to which the firm receiving the support is generally better off (e.g., Jørgensen and Zaccour, 2014). Note that $V_{R \mid \phi=0.265}^{N}=V_{R \mid \phi=0.3075}^{C}$. This highlights the idea that the $R$ 's profits without a cooperative program under a certain sharing parameter (e.g., $\phi=0.265$ ) and $R$ 's profits with a cooperative program and high sharing parameter values (e.g., $\phi=0.3075)$ coincide. Therefore, $R$ can be indifferent between cooperating with a high share and avoiding a cooperative program with low shares. When firms negotiate the contract terms, retailers should know that receiving a support and getting a smaller fraction of revenues can be equivalent to receiving no support and getting a larger fraction of revenues. This is relevant for retailers when they have to decide whether to enter into collaboration with other parties or not.

$$
<<\text { Insert Figure } 7 \text { here }>>
$$


Comparison of the results in Figures 6 and 7 indicates that the sharing parameter values that make a cooperative program feasible and preferable for both firms $M$ and $R$ is very tiny. At equilibrium, both firms maximize their profits under a cooperative program when $\phi \in(\underline{\phi}, \bar{\phi})$, thus a cooperative advertising program is profit-Pareto-improving only inside this region of sharing parameter values. The latter corresponds to the sharing parameter value range that makes the cooperative solution feasible and profitable for $M$. During the negotiation process, firms should aim at fixing the sharing parameter within this range. When collaboration is not on the menu, reaching an agreement will be extremely difficult as $\frac{\partial V_{M_{S S}}^{C}}{\partial \phi}>0$ and $\frac{\partial V_{R_{S S}}^{C}}{\partial \phi}<0$. Our general findings suggest that when the supply chain problem involves operational issues such as production and inventory, beside marketing issues such as pricing and advertising, the region in which a cooperative program by means of a support program turns out to be economically worthwhile is very limited and the adoption of this coordination mechanism very challenging.

\subsubsection{Time-trajectories analysis}

The comparisons of the value functions at the steady-state as earlier considered assume that we compute the accumulated profits along the optimal trajectory of the inventory level when the initial inventory is already at the steady-state value. In this subsection, we draw the strategies, demand, inventory level and profits along the optimal time-path of the inventory level when the initial inventory is greater than the steady state, specifically, $\bar{Y}_{0}=15$. Because the inventory level is a proxy of the market potential, we consider that it is logical to assume that the firms would use a high initial inventory level to avoid stockouts.

We display the full analysis on the trajectories for strategies, demand, state variable and profits in Appendix C. As expected, we obtain the transition towards the steady-state values, that is, the analysis along the optimal time-paths converging towards the steady state. We show that the results established at the steady state can be replicated when the initial inventory level is higher or equal to the steady state. Given an initially high value of the inventory $\left(\bar{Y}_{0}=15\right)$, the inventory decreases towards its steady-state value. All the decision variables also monotonously decrease towards their steady-state values, both for the $N$-Scenario and the $C$-Scenario. The optimal time-paths of the benchmark and the cooperative advertising scenarios never cross. From the previous analysis, we know that at the steady state all variables take a larger value under the $C-$ Scenario than under the $N$-Scenario. Therefore, our findings and managerial implications can be always replicated when the initial value of the inventory level is higher or equal to the steady-state value.

\section{$5 \quad$ Special cases}

In this section, we develop four special cases, which are variants of our original model. In particular, we develop three special cases based on the use of a classical wholesale price contract under a VMI policy, the use of different sharing parameters for costs and revenues, the presence of inventory obsolescence, as well as the relationship between pricing and promotion in the demand function.

\subsection{Special case $I$ - Wholesale price with VMI and a cooperative program}

In this section, we develop a dynamic game that conserves all ingredients of the model developed in Eqs. (5) - (6) but in which firms use a classical wholesale price contract to manage the financial flows. At each instant in time, $t, M$ charges a wholesale price $\omega(t)$ to $R$, which is a new positive control variable such as 
$\omega(t)<p(t) . R$ sets the retail price without sharing anything with $M$. This scenario allows us to isolate the VMI effects from the coordination effects, that is, understand if the findings displayed in Section 4 depend on the inventory policy or on the coordination mechanism. Indeed, we expect that a wholesale price contract (WPC) is less efficient than a revenue sharing contract (RSC), as largely supported by the literature on supply chain coordination exploring the framework of a simple supply chain (e.g., Cachon and Lariviere, 2005). Nevertheless, we aim at exploring the efficiency of cooperative programs under a WPC and VMI policy. To pursue this target, we develop a WPC game without a cooperative program, which is described as follows:

$$
\begin{aligned}
& \bar{J}_{M}^{N}=\max _{u(t), \omega(t)} \int_{0}^{+\infty} e^{-r t}\left\{D(t) \omega(t)-\frac{h(u(t)-k)^{2}}{2}-c_{R} \phi Y(t)\right\} d t, \\
& \bar{J}_{R}^{N}=\max _{p(t), A(t)} \int_{0}^{+\infty} e^{-r t}\left\{D(t)(p(t)-\omega(t))-\frac{(A(t))^{2}}{2}-c_{R}(1-\phi) Y(t)\right\} d t, \\
& \text { s.t. }: \quad \dot{Y}(t)=u(t)-D(t), \quad Y(0)=Y_{0} .
\end{aligned}
$$

To find the equilibrium of this game, we followed the same procedure as described in Proposition 1 and Appendix A.

Proposition 3 The equilibrium strategies in the benchmark scenario (no cooperative advertising) with a wholesale price contract are given by:

$$
\begin{aligned}
\bar{u}^{N}(Y) & =\frac{\bar{M}_{1}^{N} Y+\bar{M}_{2}^{N}+h k}{h} \\
\bar{\omega}^{N}(Y) & =\frac{Y\left(1+\left(\bar{M}_{1}^{N}-\bar{R}_{1}^{N}\right) \beta\right)+\left(\bar{M}_{2}^{N}-\bar{R}_{2}^{N}\right) \beta}{2 \beta}, \\
\bar{A}^{N}(Y) & =\frac{\left(Y\left(\alpha-\left(\bar{M}_{1}^{N}+\bar{R}_{1}^{N}\right) \beta\right)-\left(\bar{M}_{2}^{N}+\bar{R}_{2}^{N}\right) \beta\right) \gamma}{2\left(2 \beta-\gamma^{2}\right)} \\
\bar{p}^{N}(Y) & =\frac{\left(\bar{M}_{2}^{N}+\bar{R}_{2}^{N}\right) \beta\left(\beta-\gamma^{2}\right)+Y\left(\alpha\left(3 \beta-\gamma^{2}\right)+\left(\bar{M}_{1}^{N}+\bar{R}_{1}^{N}\right) \beta\left(\beta-\gamma^{2}\right)\right)}{2 \beta\left(2 \beta-\gamma^{2}\right)},
\end{aligned}
$$

where $\bar{M}_{i}^{N}, \bar{R}_{i}^{N}, i=1, \ldots, 3$ are the coefficients of the value functions $\bar{V}_{M}^{N}(Y)$ and $\bar{V}_{R}^{N}(Y)$ given by

$$
\begin{aligned}
& \bar{V}_{M}^{N}(Y)=\bar{M}_{1}^{N} \frac{Y^{2}}{2}+\bar{M}_{2}^{N} Y+\bar{M}_{3}^{N}, \\
& \bar{V}_{R}^{N}(Y)=\bar{R}_{1}^{N} \frac{Y^{2}}{2}+\bar{R}_{2}^{N} Y+\bar{R}_{3}^{N} .
\end{aligned}
$$

These coefficients depend on the model's parameters and on the value functions describing the optimal profits along the whole optimal inventory trajectory $\left.\bar{Y}^{N}(t)\right)$.

The optimal time-path of the inventory reads:

$$
\bar{Y}^{N}(t)=\left(Y_{0}-\bar{Y}_{S S}^{N}\right) e^{\left(\frac{\bar{M}_{1}^{N}\left(h \beta^{2}+2\left(2 \beta-\gamma^{2}\right)\right)-h \beta\left(1-\bar{R}_{1}^{N} \beta\right)}{2 h\left(2 \beta-\gamma^{2}\right)}\right) t}+\bar{Y}_{S S}^{N}
$$


where

$$
\bar{Y}_{S S}^{N}=\frac{2 \bar{M}_{2}^{N}\left(2 \beta-\gamma^{2}\right)+h\left(\left(\bar{M}_{2}^{N}+\bar{R}_{2}\right) \beta^{2}+2 k\left(2 \beta-\gamma^{2}\right)\right)}{h \beta\left(1-\bar{R}_{1}^{N} \beta\right)-\bar{M}_{1}^{N}\left(h \beta^{2}+2\left(2 \beta-\gamma^{2}\right)\right)}
$$

is the steady-state inventory level. This steady state is globally asymptotically stable if and only if $\frac{\bar{M}_{1}^{N}\left(h \beta^{2}+2\left(2 \beta-\gamma^{2}\right)\right)-h \beta\left(1-\bar{R}_{1}^{N} \beta\right)}{2 h\left(2 \beta-\gamma^{2}\right)}<0$.

Proof. The proof follows the same steps as the proofs of Propositions 1 and 3 .

The benchmark game will then be compared to the cooperative program game, in which $M$ optimally sets the participation rate, $B(t)$. The firms' problem is described as follows:

$$
\begin{aligned}
& \bar{J}_{M}^{C}=\max _{u(t), \omega(t), B(t)} \int_{0}^{+\infty} e^{-r t}\left\{D(t) \omega(t)-\frac{h(u(t)-k)^{2}}{2}-\frac{B(t)}{2}(A(t))^{2}-c_{R} \phi Y(t)\right\} d t, \\
& \bar{J}_{R}^{C}=\max _{p(t), A(t)} \int_{0}^{+\infty} e^{-r t}\left\{D(t)(p(t)-\omega(t))-\frac{(1-B(t))}{2}(A(t))^{2}-c_{R}(1-\phi) Y(t)\right\} d t, \\
& \text { s.t. } \quad: \quad \dot{Y}(t)=u(t)-D(t), \quad Y(0)=Y_{0} .
\end{aligned}
$$

When deriving the equilibrium for this game, we use the benchmark parameter values as in (19) and numerically find that the participation rate gives unfeasible solutions at the steady-state. Therefore, we conclude that the cooperative program under a wholesale price contract is never feasible for all possible combinations of parameter values. This is due to the fact that the scarce coordination among firms imposes $M$ to be far from his operational target while the additional participation efforts are very detrimental for his profits. Thus, a WPC does not offer any opportunities to coordinate the chain when VMI and cooperative programs are offered together.

\subsection{Special case $I I$ - VMI with a RSC and different sharing parameters for revenues and inventory costs}

So far, we discuss our settings by assuming that the supply chain firms use the same sharing rule, $\phi$, for both revenues and inventory costs. In this section, we develop a special case differentiating between the sharing rule for revenues, $\phi_{r}$, and the sharing rule for the inventory cost, $\phi_{c}$. Note that the term $c_{R} \phi_{c} Y$ in $M$ 's profit function (in Eq. (5)) and the term $c_{R}\left(1-\phi_{c}\right) Y(t)$ in $R$ 's profit function (in Eq. (6)) are the only components of the model that are influenced by the use of different sharing parameters. Consequently, the strategies displayed in Eqs. (7)-(9) remain the same while it suffices to fix $\phi=\phi_{r}$. Finally, the expressions $-2 h c_{R} \phi$ and $-h c_{R}(1-\phi)$ in the second and fifth equations of the Riccati systems for scenarios $N$ and $C$ (see Appendices A and B) become $-2 h c_{R} \phi_{c}$ and $-h c_{R}\left(1-\phi_{c}\right)$, respectively, while $\phi=\phi_{r}$ for all other parameters. With this change, the results generated with our original model in Figures 6 and $7\left(\phi_{c}=\phi_{r}\right)$ become as displayed in Figures 8-11 $\left(\phi_{c} \neq \phi_{r}\right)$. Accordingly, the following remarks can be made about the results:

1. Given a fixed sharing rule for inventory cost (e.g., $\phi_{c}=0.2675$ ), firms have large chances to be economically better-off through a cooperative program. In Figure 8, the region of $\phi_{r}$ values in which $M$ obtains larger profits enlarges comparatively to the ones in Figure 6, as the maximum sharing parameter values moves from 0.2725 to 0.2825 . In Figure $9, R$ shows the same preferences as in Figure 7 , thus she always opts for the implementation of a cooperative program, independent of using similar or different sharing rules for profits and inventory costs. 
2. When fixing the sharing rule of the revenues (e.g., $\phi_{r}=0.2675$ ), firms show reverse preferences in Figures 10-11, comparatively to Figures 6 and 7. Specifically, $M$ 's profits always increase in $\phi_{c}$ while $R$ 's profits always decrease in $\phi_{c}$. This is very much intuitive and expected as it relates to sharing costs. Interestingly, from Figures 10 and 11, we can identify three ranges of $\phi_{c}$ for which firms' preferences change:

- When $\phi_{c}<0.275$, there exists a Pareto-improving region in which both firms are economically betteroff through a cooperative program. Therefore, for low values of revenue sharing parameters, firms should cooperate under a VMI policy.

- When $\phi_{c} \in[0.275,0.295), M$ is not economically interested in a cooperative program, while $R$ still prefers this option. This highlights the need for a complementary coordination program to implement a VMI as cost-profit sharing associated to a cooperative program are not sufficient to coordinate a chain.

- When $\phi_{c} \geq 0.295$, all firms are economically worse-off with the cooperative program.

$$
\begin{aligned}
& <<\text { Insert Figure } 10 \text { here }>> \\
& <<\text { Insert Figure } 11 \text { here }>>
\end{aligned}
$$

\subsection{Special case $I I I$ - VMI with a RSC and inventory obsolescence}

In this section, we investigate the effect of inventory obsolescence on firms' profits and on cooperative programs effectiveness. So far, we assumed that the products in inventory have a very long shelf life, i.e., do not expire, which refers to the case of durable goods. Therefore, inventory $Y(t)$ is fully available to consumers at time $t$. This assumption is in line with sectors like iron and furniture in which manufacturers can work in make-tostock without considering the inventory obsolescence issue. Hereby, we relax this assumption and model the inventory obsolescence by adding the positive parameter $\alpha$ in the demand function. $\alpha$ denotes the natural inventory obsolescence in a specific moment in time and informs on the amount of goods that is not available to consumers because the goods become obsolete. Therefore, we fix $\alpha \leq 1$ when inventory is subjected to obsolescence. Obsolescence negatively affects the demand function (e.g., Teunter et al., 2011), which modifies as follows:

$$
D(Y, p, A)=\alpha Y(t)-\beta p(t)+\gamma A(t) .
$$

This demand formulation implies that the goods at the $R$ 's store are $\alpha Y(t)$. Strategies, profits and inventory dynamics in the $N$ and $C$ scenarios can be derived by following the same procedure used in Propositions 1 and 2. Then, we study the problem at the steady state and focus here on the analysis of profits. We use $\alpha=0.85,0.9,0.95$, corresponding to an obsolescence rate of $15 \%, 10 \%$ and $5 \%$ respectively. Firms' profits are displayed in Figure 12, which provides us with the following insights:

1. Intuitively, compared to the case with no inventory obsolescence $(\alpha=1)$, obsolescence results in losses in inventory and demand, which leads to lower profits for all supply chain firms.

2. Figure 12 shows that $R$ always prefers the implementation of a cooperative program. This result is similar to the one generated without inventory obsolescence effects (Figure 7). Hence, $R$ always benefits from a cooperative program independent of inventory obsolescence.

3. $M$ adjusts his preferences for a cooperative program depending on the sharing parameter. In particular, the faster the inventory obsolescence, the lower the sharing parameter that $M$ prefers. 
4. Increasing values of inventory obsolescence increase the chances to use a cooperative program to coordinate firms' targets. As it is a supply chain issue, all firms get involved to coordinate and mitigate its negative effects.

$$
<<\text { Insert Figure } 12 \text { here }>>
$$

\subsection{Special case $I V$ - VMI with a RSC and $\beta \gtreqless \gamma$}

In the numerical analysis that we developed earlier, we assumed the parameter values to be fixed in the demand function such that $\beta>\gamma$, meaning that demand is more sensitive to price than to promotion. In this section, we relax this assumption and assume that $\beta$ can be higher or lower than $\gamma$. We set $\gamma=1.5$ and change $\beta=1.4,1.5,1.6$. The analysis of profits, which is displayed in Figure 13, leads to the following observations:

1. When the price effect is lower than the promotion's effect $(\beta<\gamma)$, both firms gain higher profits in each game. Intuitively, the higher the importance of promotion over pricing, the higher firms' profits due to the lower consumers' sensitivity to price.

2. $R$ invests more in promotion and always sponsors the adoption of a cooperative program to coordinate the chain. She always finds it convenient to implement the cooperative program, thus following the results displayed in Figure 7.

2. For $\beta<\gamma$, a cooperative program does not become more appealing to coordinate the chain. Consistently with Figure 13, $M$ is willing to implement a cooperative program only for small regions of $\phi$, hence following the same results as in Figure 6. Therefore, coordination through a cooperative program with VMI and RSC is a real challenge, independent of the consumers' sensitivity to price and promotion. However, note that the region of interest is larger than in the benchmark case, which shows that there is a higher chance to benefit from coordination through a cooperative program when the interested strategy (promotion in our games) is more important than others in developing sales.

$$
<<\text { Insert Figure } 13 \text { here }>>
$$

\section{Conclusions}

The cooperative advertising literature has mostly studied the effects of these programs considering marketing (demand-side) variables, such as, advertising and prices. However, the operations management literature has long noted the importance of integrating these marketing decisions to operational (supply-side) variables related to production and inventory management. We consider a supply chain where a Vendor Managed Inventory (VMI) agreement is complemented by a consignment contract with revenue sharing. We develop a model where both marketing and operational variables are considered. We solve a differential Stackelberg game where the manufacturer $(M)$ is the leader and the retailer $(R)$ is the follower. The equilibrium solutions for pricing, advertising effort and production rate are then obtained in two games. The first game is a benchmark scenario where no cooperative advertising is offered. In the second game, $M$ offers the cooperative program to support $R$ 's advertising efforts. We summarize our findings in a few points:

1. Inventory is used as a marketing tool to ensure a certain market potential. Through a cooperative advertising program, firms are willing to do more: $M$ produces more, $R$ promotes more, the supply chain keeps larger inventories, while $R$ optimally manages the trade-off between pricing and promotion. 
2. Contrary to the marketing literature that lauds the use of a cooperative advertising program to make all supply chain members economically better off, the presence of a VMI policy complemented by a consignment contract with revenue sharing makes a cooperative advertising program very difficult to implement. Our findings suggest that there is a very small region in which all firms can improve their profits by adopting a support program, thus highlighting the serious difficulties that companies can face when the ingredients that we used in our model are all simultaneously present. $M$ will decide to support $R$ 's advertising efforts only when the sharing parameter is negotiated ex-ante and is fixed within some boundaries. $R$ is more favorable towards the presence of a cooperative program and will prefer to have support for her advertising efforts in most cases. Nevertheless, she will be indifferent between advertising support with high sharing and no advertising support with low sharing. Overall, the implementation of a support program is rather complicated when operational and marketing devices are considered simultaneously.

3. The presence of a cooperative program stabilizes inventory, which becomes less dependent on the sharing parameter. When $M$ is economically better off with a cooperative advertising program, the supply chain holds higher stocks of inventory, thus ensuring larger business opportunities.

4. The implementation of a cooperative advertising program reverses the relationship between advertising efforts and the sharing parameter. In a non-cooperative setting, larger share means lower economic resources for $R$, who consequently shows less willingness to spend on advertising. Nevertheless, when a cooperative program is in place, $R$ invests more in advertising even when the share she retains decreases due to the presence of a support program whose amplitude increases with the sharing parameter.

Further, we develop some special cases to investigate the convenience of using a VMI policy under a traditional wholesale price contract, the use of different sharing parameters for costs and revenues, the role of inventory obsolescence and the effects of pricing and promotion in the demand function. We find that cooperative programs under a wholesale price contract are never feasible. Consequently, firms are not able to coordinate their chain through a cooperative program when a VMI and a wholesale price contract coexist. We discover that supply chains can increase the suitability of revenue sharing within the contest of VMI and cooperative programs when differentiating between sharing parameters for costs and revenues. Working on these two contractual terms makes a cooperative program more appealing. Inventory obsolescence harms the whole supply chain profitability, thus firms can better exploit a cooperative program to improve their economic performance. Finally, supply chains have few chances to use cooperative programs in the context of VMI and consignment contracts with revenue sharing, independent of the consumers' sensitivity to price and promotion.

This work has some limitations that can be tackeled in future research. To keep the model simple, we have focused on a bilateral monopolistic supply chain. Even with such a simplistic chain structure, we obtained complex results that could not have been analyzed analytically. Future research can explore the effect of competition at the retailing, manufacturing or both levels. Also, different demand functions that account for other strategies can be studied. For example, the manufacturer's brand advertising can be modeled and its effect on brand goodwill added to the model. Further, we assume that $R$ decides the selling price, while in many sectors (e.g., electronics, automotive), $M$ sets the final selling price so that all retailers sell the same product at the same price. Modelling the game with this assumption may completely change our results. We assume that our supply chain reflects a brick-and-mortar channel, in which $M$ manages the inventory held at $R$ 's level. One can relax this assumption by assuming that $M$ works in a make-to-stock context and keeps the inventory, while $R$ sells products under a purchase-to-order setting. One can even assume that both players keep inventory in stock (as in Jørgensen, 1986) while the inventory at $R$ 's level represents 
the market potential. This modification will already provide an additional contribution to the literature in which the level of inventory at $R$ 's store and the market potential have always been modelled separately (e.g., Jørgensen, 1986; El Ouardighi et al., 2008; Kogan and Tapiero, 2007).

\section{References}

[1] Adida, E., \& Ratisoontorn, N. (2011). Consignment contracts with retail competition. European Journal of Operational Research, 215 (1), 136-148.

[2] Aust, G., \& Buscher, U. (2014). Cooperative advertising models in supply chain management: A review. European Journal of Operational Research, 234 (1), 1-14.

[3] Battini, D., Grassi, A., Persona, A., \& Sgarbossa, F. (2010). Consignment stock inventory policy: Methodological framework and model. International Journal of Production Research, 48 (7), 2055-2079.

[4] Ben-Daya, M., Hassini, E., Hariga, M., \& AlDurgam, M. M. (2013). Consignment and vendor managed inventory in single-vendor multiple buyers supply chains. International Journal of Production Research, 51 (5), 1347-1365.

[5] Bernstein, F., Chen, F., \& Federgruen, A. (2006). Coordinating supply chains with simple pricing schemes: The role of vendor-managed inventories. Management Science, 52 (10), 1483-1492.

[6] Borrell Associates Report (2015). Available at http://www2.netsertive.com/l/30602/2015-08-11/3z8jbc. Accessed on Oct 272016.

[7] Cachon, G. P. (2004). The allocation of inventory risk in a supply chain: Push, pull, and advancepurchase discount contracts. Management Science, 50 (2), 222-238.

[8] Cachon, G. P., \& Lariviere, M. A. (2005). Supply chain coordination with revenue-sharing contracts: Strengths and limitations. Management Science, 51 (1), 30-44.

[9] Chen, L. T. (2013). Dynamic supply chain coordination under consignment and vendor-managed inventory in retailer-centric B2B electronic markets. Industrial Marketing Management, 42 (4), 518-531.

[10] Cho, R. K., \& Gerchak, Y. (2005). Supply chain coordination with downstream operating costs: Coordination and investment to improve downstream operating efficiency. European Journal of Operational Research, 162 (3), 762-772.

[11] De Giovanni, P. (2011). Quality improvement vs. advertising support: Which strategy works better for a manufacturer? European Journal of Operational Research, 208 (2), 119-130.

[12] De Giovanni, P. (2016). Coordination in a distribution channel with decisions on the nature of incentives and share-dependency on pricing. Journal of the Operational Research Society, 67 (8), 1034-1049.

[13] De Giovanni, P., \& Zaccour, G. (2013). Cost-revenue sharing in a closed-loop supply chain. In Advances in Dynamic Games (pp. 395-421). Birkhäuser Boston.

[14] Dong, Y., \& Xu, K. (2002). A supply chain model of vendor managed inventory. Transportation Research Part E: Logistics and Transportation Review, 38 (2), 75-95. 
[15] El Ouardighi, F., Jørgensen, S., \& Pasin, F. (2008). A dynamic game of operations and marketing management in a supply chain. International Game Theory Review, 10 (4), 373-397.

[16] Erickson, G. M. (2012). Transfer pricing in a dynamic marketing-operations interface. European Journal of Operational Research, 216 (2), 326-333.

[17] He, X., Prasad, A., \& Sethi, S. P. (2009). Cooperative advertising and pricing in a dynamic stochastic supply chain: Feedback Stackelberg strategies. Production and Operations Management, 18, 78-94.

[18] Huang, Z., \& Li., S.X. (2001). Co-op advertising models in manufacturer-retailer supply chains: A game theory approach. European Journal of Operational Research, 135 (3), 527-544.

[19] Hung, J. S., Fun, Y. P., \& Li, C. C. (1995). Inventory management in the consignment system. Production and Inventory Management Journal, 36 (4), 1.

[20] Jørgensen, S. (1986). Optimal production, purchasing and pricing: A differential game approach. European Journal of Operational Research, 24 (1), 64-76.

[21] Jørgensen, S., Sigué, S.P., \& Zaccour, G. (2000). Dynamic cooperative advertising in a marketing channel. Journal of Retailing, 76, 71-92.

[22] Jørgensen, S., Taboubi, S., Zaccour, G. (2003). Retail promotions with negative brand image effects: Is cooperation possible? European Journal of Operational Research, 150, 395-405.

[23] Jørgensen, S., \& Zaccour, G. (2014). A survey of game-theoretic models of cooperative advertising. European Journal of Operational Research, 237, 1-14.

[24] Karray, S. (2013). Periodicity of pricing and marketing efforts in a distribution channel. European Journal of Operational Research, 228, 635-647.

[25] Karray, S. (2015). Cooperative promotions in the distribution channel. Omega, The International Journal of Management Science, 51, 49-58.

[26] Karray, S.,Martín-Herrán, G., \& Zaccour, G. (2017). Assessing the profitability of cooperative advertising programs in competing channels. International Journal of Production Economics, 187, 142-158.

[27] Karray, S., \& Zaccour, G. (2006). Could co-op advertising be a manufacturer's counterstrategy to store brands? Journal of Business Research, 59 (9), 1008-1015.

[28] Karray, S., \& Zaccour, G. (2005). A differential game of advertising for national and store brands. In A. Haurie \& G. Zaccour (Eds.), Dynamic games: Theory and applications (pp. 213-230). Berlin: Springer.

[29] Kaya, O. (2010). Incentive and production decisions for remanufacturing operations. European Journal of Operational Research, 201 (2), 442-453.

[30] Kogan, K., \& Tapiero, C. S. (2007). Supply chain games: operations management and risk valuation (Vol. 113). Springer Science \& Business Media.

[31] Li, S. X., Huang, Z., Zhu, J., \& Chau, P. Y. (2002). Cooperative advertising, game theory and manufacturer-retailer supply chains. Omega, The International Journal of Management Science, 30 (5), 347-357. 
[32] Li, S., \& Hua, Z. (2008). A note on channel performance under consignment contract with revenue sharing. European Journal of Operational Research, 184 (2), 793-796.

[33] Li, S., Zhu, Z., \& Huang, L. (2009). Supply chain coordination and decision making under consignment contract with revenue sharing. International Journal of Production Economics, 120 (1), 88-99.

[34] Liu, B., Cai, G., \& Tsay, A. (2014). Advertising in asymmetric competing supply chains. Production and Operations Management, 23 (11), 1845-1858.

[35] Martín-Herrán, G., \& Sigué, S. P. (2017). An integrative framework of cooperative advertising: Should manufacturers continuously support retailer advertising? Journal of Business Research, 70, 67-73.

[36] Nerlove, M., \& Arrow, K. J. (1962). Optimal advertising policy under dynamic conditions. Economica, 29, 129-142.

[37] Ru, J., \& Wang, Y. (2010). Consignment contracting: Who should control inventory in the supply chain? European Journal of Operational Research, 201 (3), 760-769.

[38] Teunter, R. H., Syntetos, A. A., \& Babai, M. Z. (2011). Intermittent demand: Linking forecasting to inventory obsolescence. European Journal of Operational Research, 214(3), 606-615.

[39] Wang, Y., Jiang, L., \& Shen, Z. J. (2004). Channel performance under consignment contract with revenue sharing. Management Science, 50 (1), 34-47.

[40] Xiao, T., \& Jin, J. (2011). Coordination of a fashion apparel supply chain under lead-time-dependent demand uncertainty. Production Planning and Control, 22 (3), 257-268.

[41] Xie, J., \& Ai, S. (2006). A note on Cooperative advertising, game theory and manufacturer-retailer supply chains. Omega, The International Journal of Management Science, 34 (5), 501-504.

[42] Yang, J., Xie, J., Deng, X., \& Xiong, H. (2013). Cooperative advertising in a distribution channel with fairness concerns. European Journal of Operational Research, 227 (2), 401-407.

[43] Yue, J., Austin, J., Wang, M., \& Huang, Z. (2006). Coordination of cooperative advertising in a two-level supply chain when manufacturer offers discount. European Journal of Operational Research, 168 (1), 65-85.

[44] Zha, Y., Zhang, J., Yue, X., \& Hua, Z. (2015). Service supply chain coordination with platform effortinduced demand. Annals of Operations Research, 235 (1), 785-806.

[45] Zhang, J., Huang, Z., Liang, L., \& Gou, Q. (2013). Supply chain coordination through cooperative advertising with reference price effect. Omega, The International Journal of Management Science, 41 (2), 345-353. 


\section{Figures}

Click here to download Manuscript: Figures.docx

Click here to view linked References

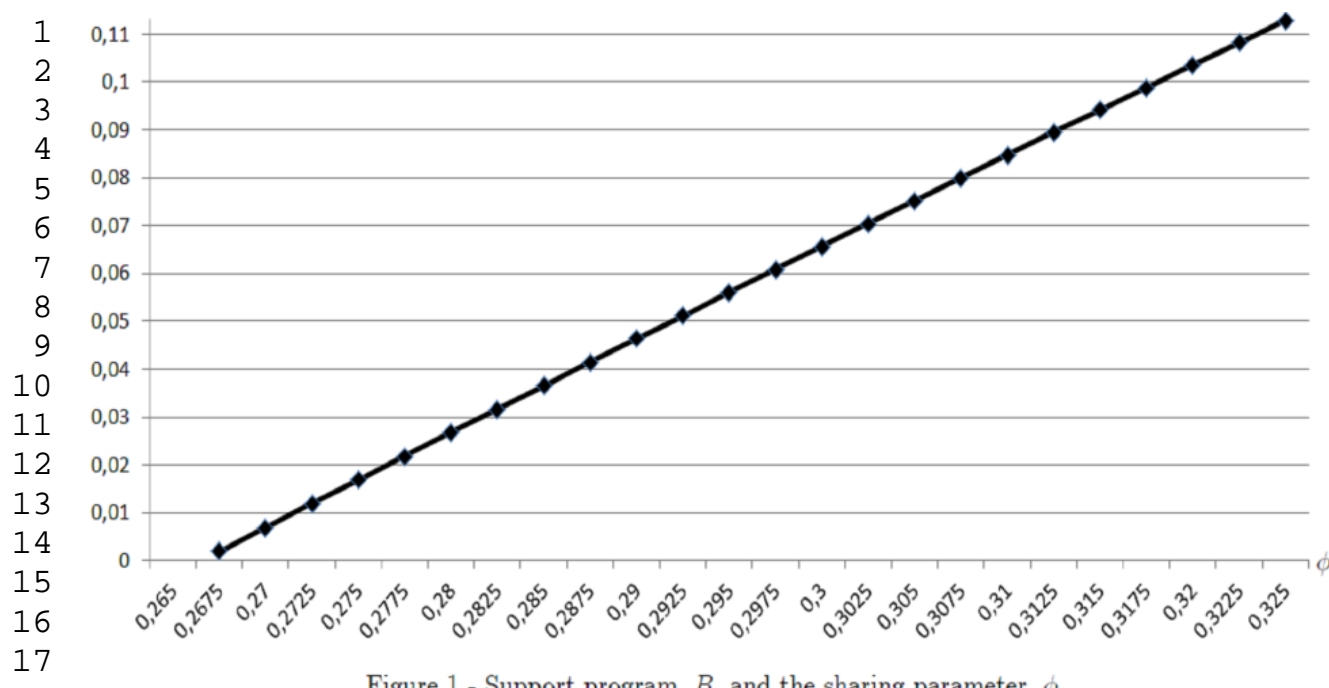

Figure 1 - Support program, $B$, and the sharing parameter, $\phi$
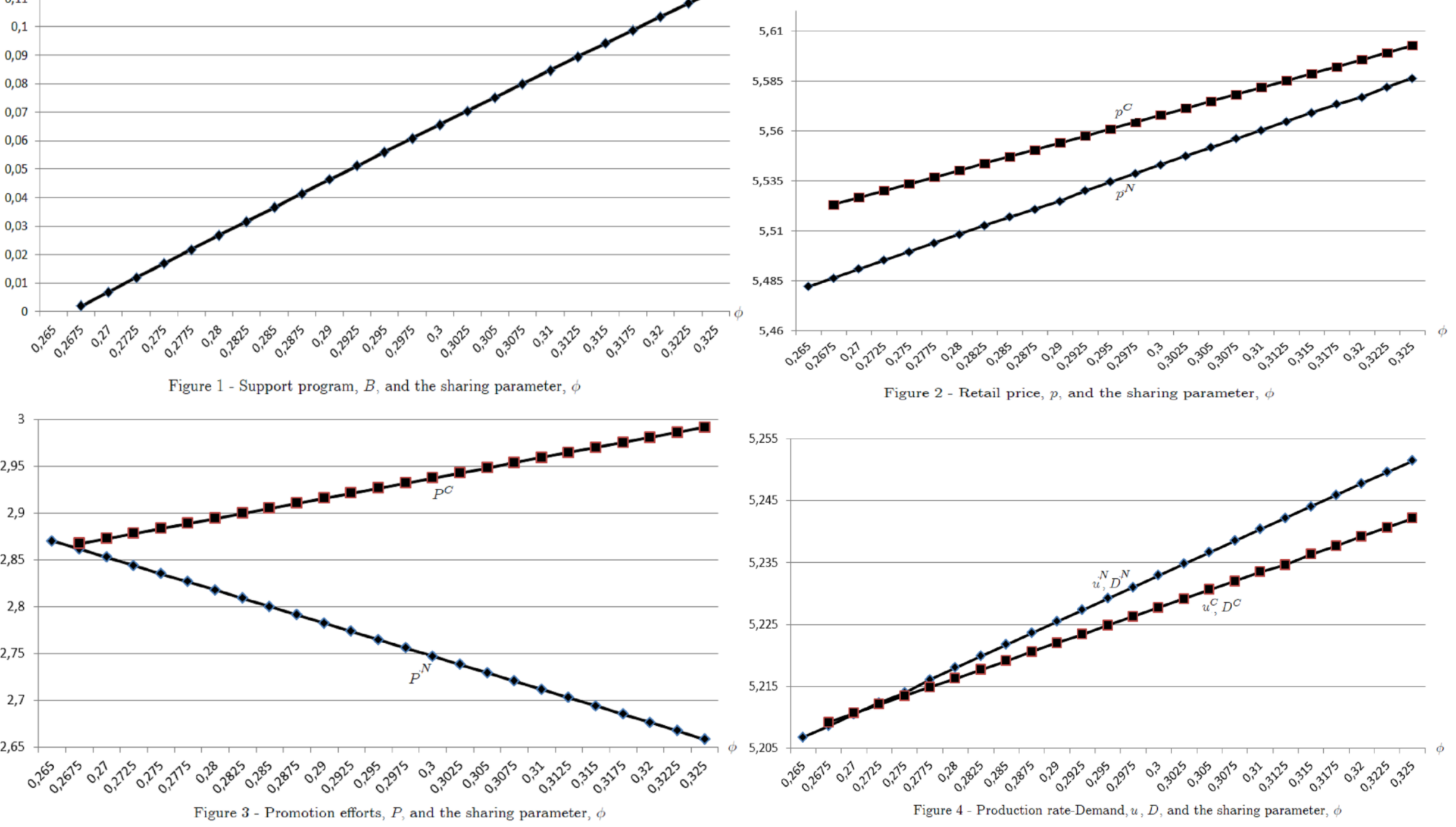

Figure 2 - Retail price, $p$, and the sharing parameter, $\phi$

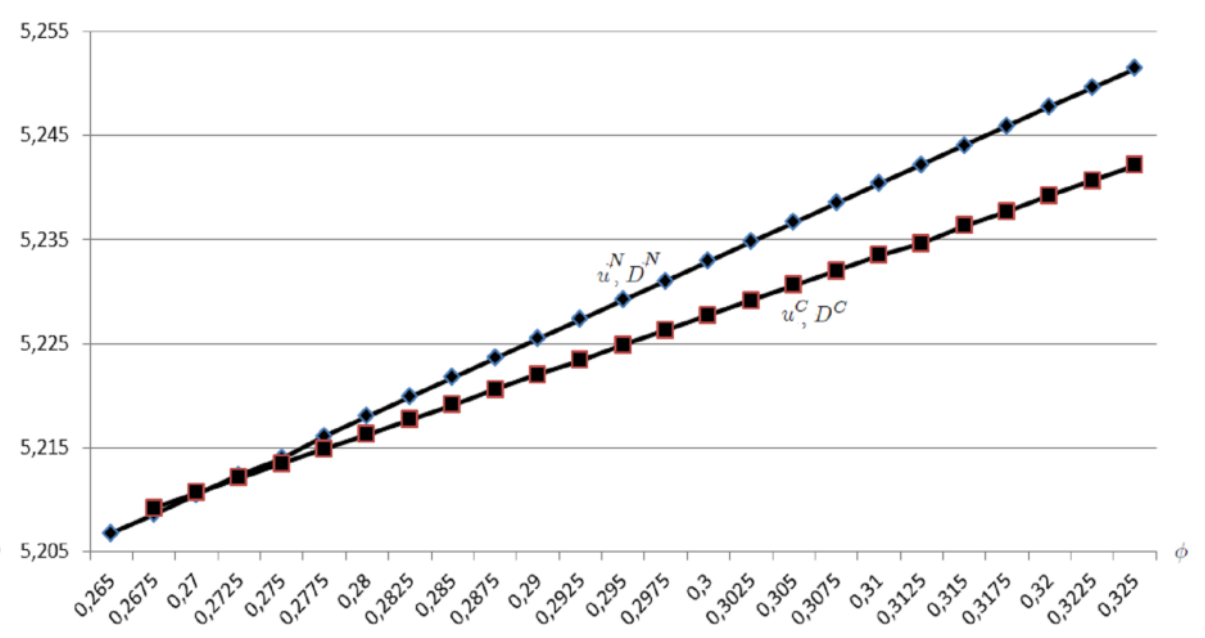

Figure 4 - Production rate-Demand, $u, D$, and the sharing parameter, $\phi$ 




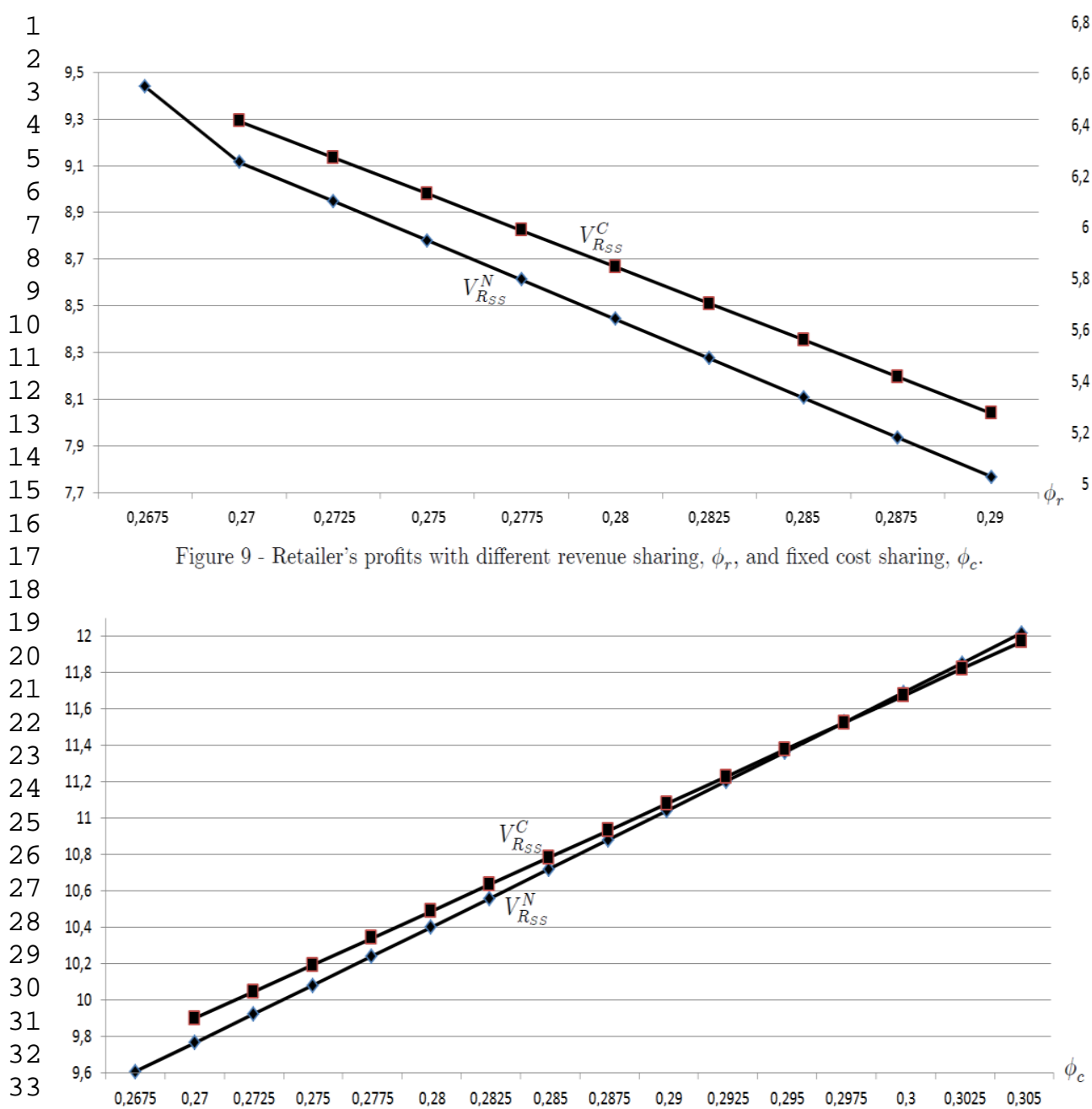

Figure 11 - Retailer's profits with different cost sharing, $\phi_{c}$, and fixed revenue sharing, $\phi_{r}$.

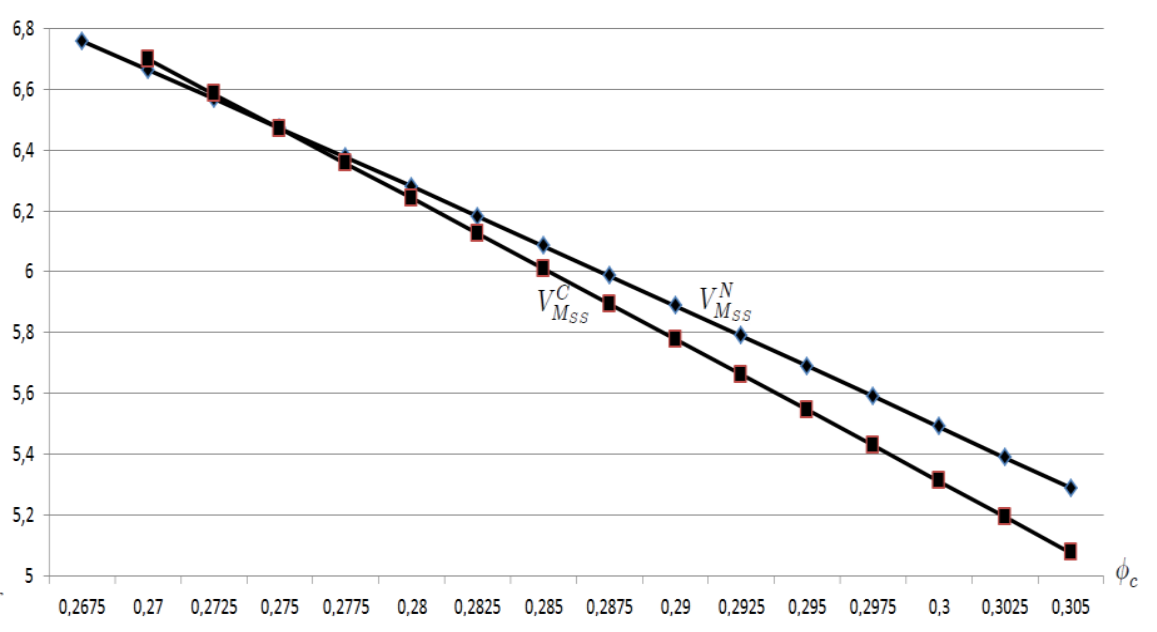

Figure 10 - Manufacturer's profits with different cost sharing, $\phi_{c}$, and fixed revenue sharing, $\phi_{r}$.

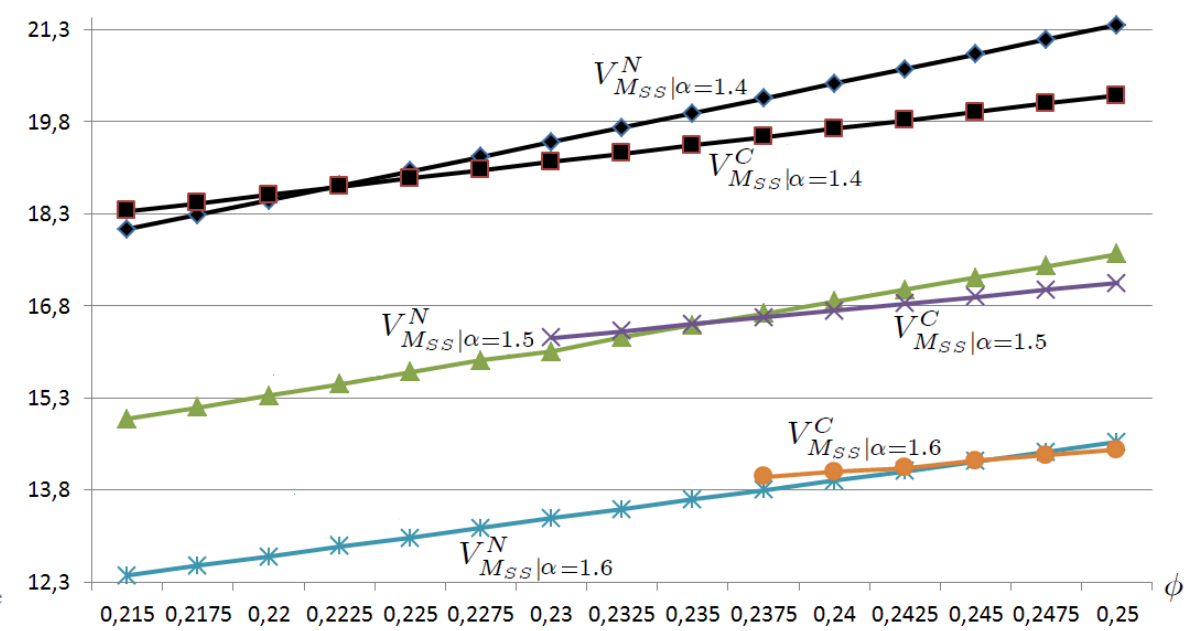

Figure 12 - M's profits under and sharing parameter, $\phi$, with different levels of $\alpha$. 


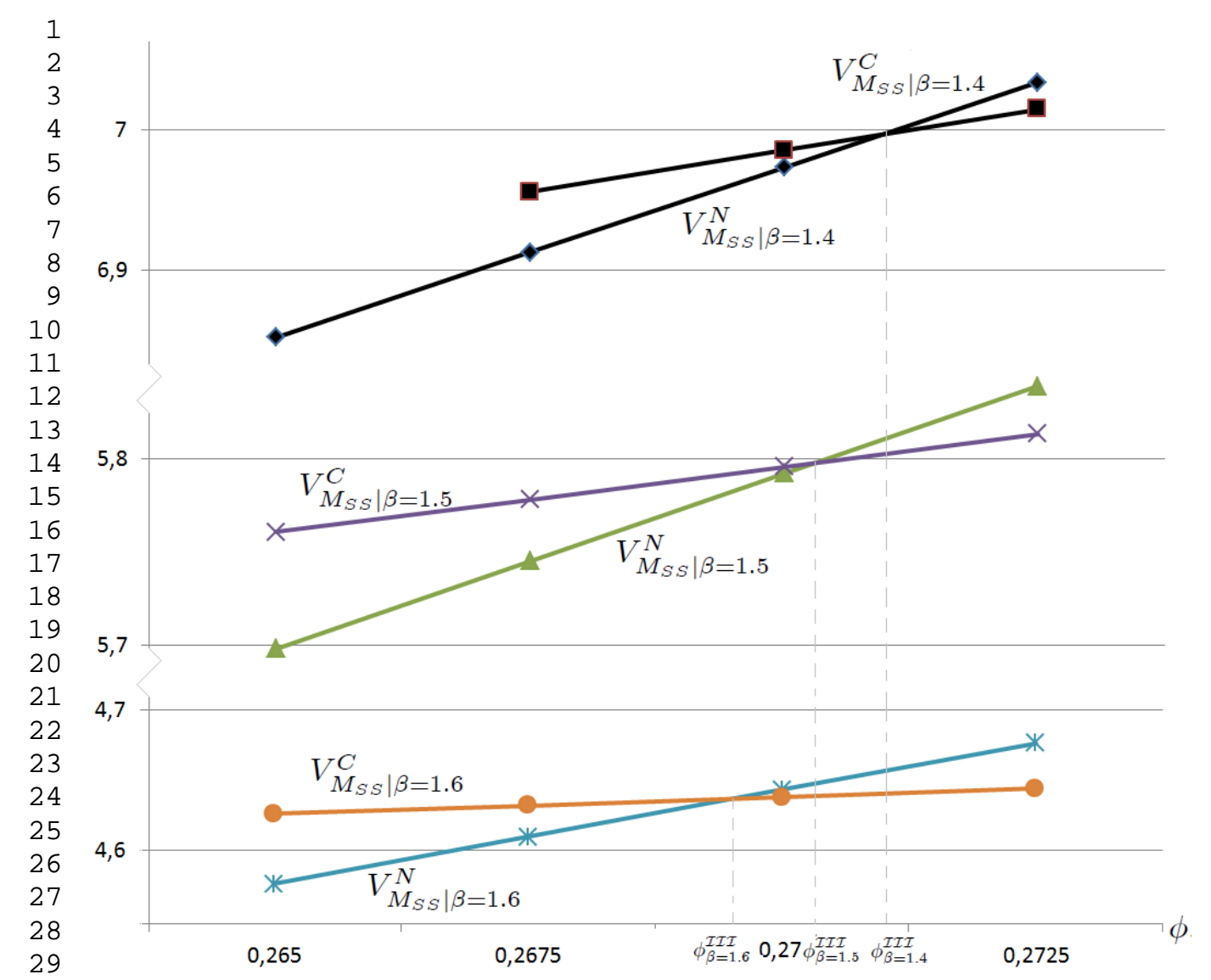

30 Figure $13-M$ 's profits under and sharing parameter, $\phi$, with different levels of $\beta$. 
1

2

3

4

5

6

7

8

9

10

11

12

13

14

15

\section{Appendix C}

We fix $Y_{0}=15$ and get the optimal time-paths state and control variables for both the benchmark and the cooperative advertising scenarios.
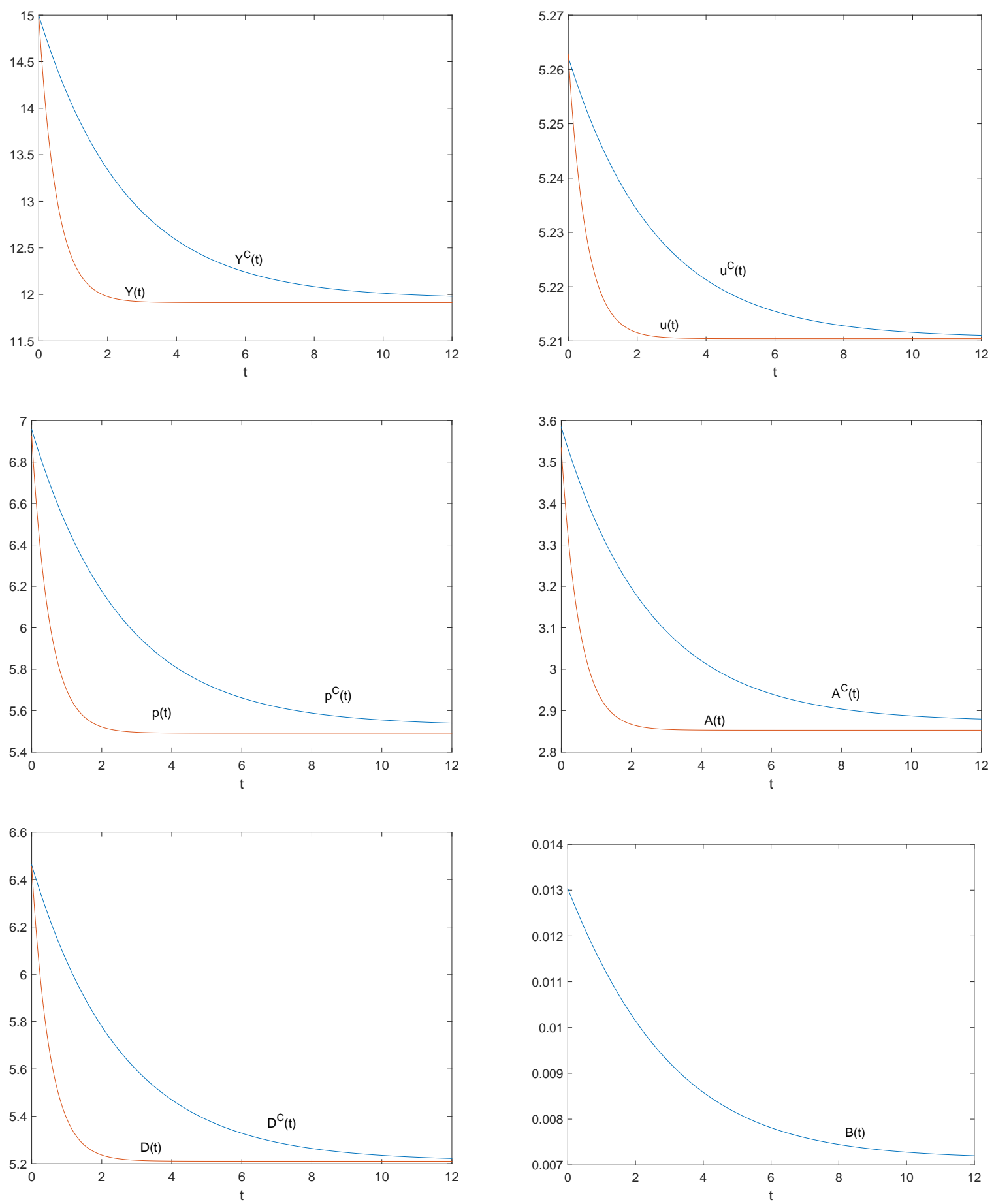


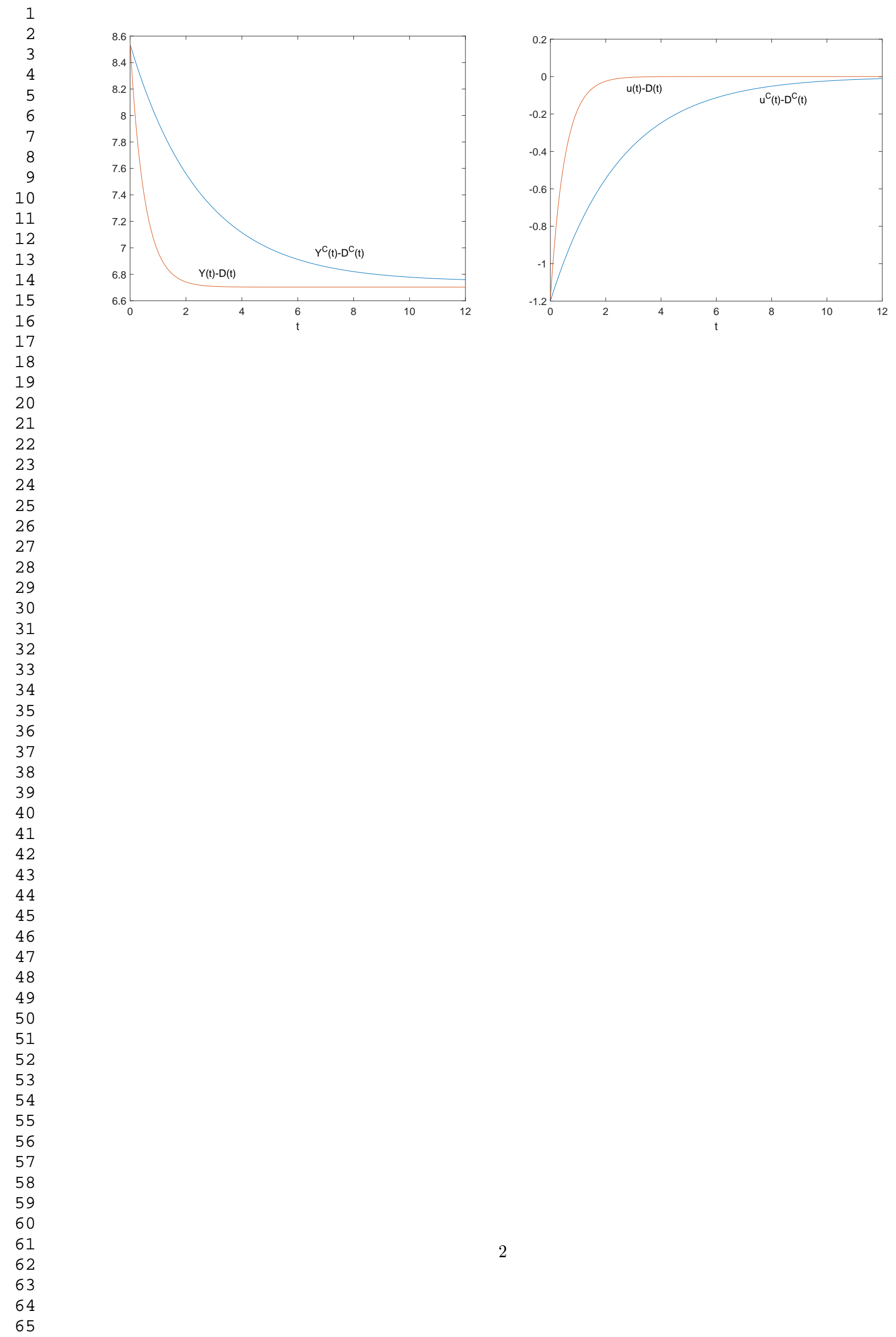


Online Appendix - Sensitivity analysis
Click here to download Supplementary

Online Appendix - Sensitivity analysis
Click here to download Supplementary Material: Online Appendix - Sensitivity analysis.pdf 
Online Appendix - Feasibility analysis
Click here to download Supplementary

Click here to download Supplementary Material: Online Appendix - Feasibility analysis.pdf 
Online Appendix - Proof of Proposition 1
Click here to download Supplementary Material: Online Appendix - Proof of propositions 1.pdf (1) f

fo

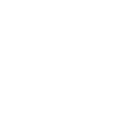

$\sqrt{10}$

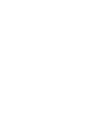
西

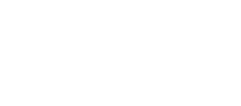

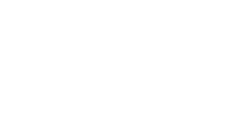
. . . . (1) (1)

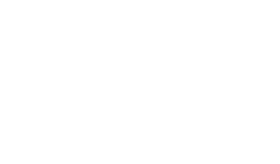

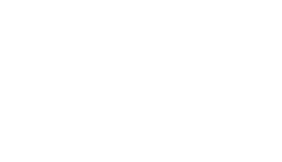

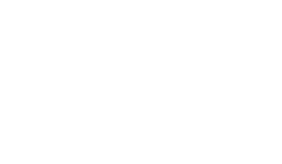

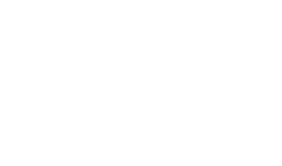

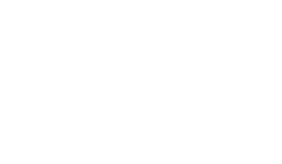

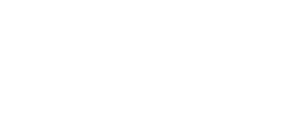
年 -

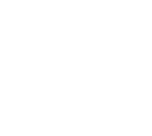

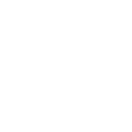

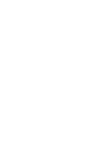

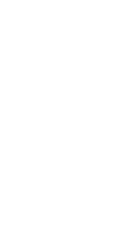
. (n)

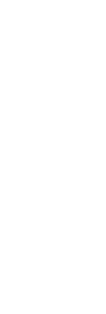

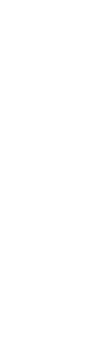

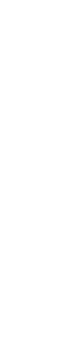

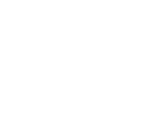
.

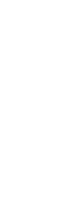

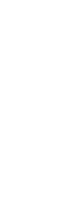
. $x^{2}+n^{2}$ (1)

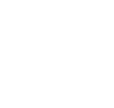


Online Appendix - Proof of Proposition 2
Click here to download Supplementary Material: Online Appendix - Proof of propositions 1 and 2.pdf

.

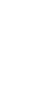

(n)

(1) (1) 


\section{LaTeX Source Files}

Click here to download LaTeX Source Files: Main text submitted to EJOR R1 with authors information June $132018 . t e x$ 